\title{
USO DO QUIMIOTERÁPICO DAUNORRUBICINA ASSOCIADO À NANOEMULSÕES LIPÍDICAS NO TRATAMENTO DA ATEROSCLEROSE EXPERIMENTAL EM COELHO
}

\author{
Tese apresentada ao Programa de \\ Cardiologia da Faculdade de Medicina da \\ Universidade de São Paulo para a \\ obtenção do título de Doutor em Ciências \\ Programa de Cardiologia \\ Orientador: Prof. Dr. Raul Cavalcante \\ Maranhão
}

Orientador: Prof. Dr. Raul Cavalcante Maranhão

São Paulo 


\title{
USO DO QUIMIOTERÁPICO DAUNORRUBICINA ASSOCIADO À NANOEMULSÕES LIPÍDICAS NO TRATAMENTO DA ATEROSCLEROSE EXPERIMENTAL EM COELHO
}

\begin{abstract}
Tese apresentada ao Programa de Cardiologia da Faculdade de Medicina da Universidade de São Paulo para a obtenção do título de Doutor em Ciências

Programa de Cardiologia

Orientador: Prof. Dr. Raul Cavalcante Maranhão
\end{abstract}

Orientador: Prof. Dr. Raul Cavalcante Maranhão

São Paulo 


\section{Dados Internacionais de Catalogaçăo na Publicação (CIP)}

Preparada pela Biblioteca da

Faculdade de Medicina da Universidade de Săo Paulo

Creproduçăo autorizada pelo autor

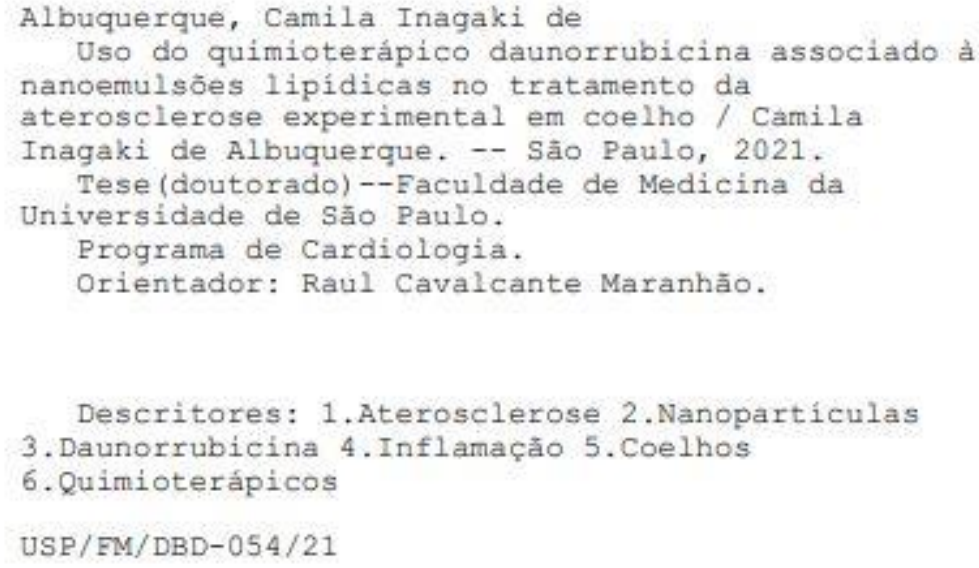

Responsável: Erinalva da Conceiçāo Batista, CRB-8 6755 


\section{DEDICATÓRIA}

Aos meus pais Natália e Paulo, por serem meu exemplo de pesquisadores e pessoas que um dia eu gostaria de ser, e por toda a dedicação, amor, incentivo que me dão.

Ao meu irmão Felipe, por todo amor, apoio e longas conversas.

Ao meu grande companheiro lgor, por sempre me incentivar e me ajudar principalmente nos momentos de incertezas, seu apoio incondicional em todos os momentos foram fundamentais para continuar seguindo. 


\section{AGRADECIMENTOS}

Ao Prof. Dr. Raul Cavalcante Maranhão pela orientação, confiança, oportunidade de realizar este trabalho, e pelos ensinamentos que contribuíram diretamente para a formação da profissional que sou hoje e me inspiram a continuar essa trajetória.

Ao Instituto do Coração da Faculdade de Medicina da Universidade de São Paulo - InCor/HCFMUSP, pela possibilidade de realizar este trabalho

À Neusa, Valdecira, Luana, Mônica e Sidnei funcionários da Pós-Graduação do programa de Cardiologia InCor, pela ajuda, empenho e disponibilidade.

À equipe de Divisão Experimental do Instituto do Coração, especialmente Dra. Edna, Dario, Pedro, Vicente, Richard e Anderson pelo auxílio e apoio na experimentação animal.

Ao Leonardo Jensen pelas análises de ecocardiograma dos animais e pela amizade.

A todos os colegas do Laboratório de Metabolismo e Lípides do InCor que participaram de forma direta e indireta desse trabalho e pelo apoio nesta trajetória.

À Elaine Rufo Tavares pela orientação que foi fundamental para este trabalho, além da dedicação e apoio que me ajudaram a crescer profissionalmente.

À Maria Carolina Guido pela contribuição intelectual e técnica nesse trabalho, além de estar sempre presente dando o seu apoio e incentivo.

À Dalila, Natália, Roberta e Pedro que tornaram essa caminhada mais fácil, participando de todos os momentos e vibrando por todas as minhas conquistas.

À minha família por serem o meu alicerce, entenderem a minha ausência, vibrarem com as minhas conquistas e me apoiarem sempre em minhas decisões.

À CAPES e FAPESP pelo apoio financeiro

E a todos aqueles que contribuíram de alguma forma para esse estudo. 


\section{NORMALIZAÇÃO}

Esta tese está de acordo com as seguintes normas, em vigor no momento desta publicação:

Referências: adaptado de International Committee of Medical Journals Editors (Vancouver).

Universidade de São Paulo. Faculdade de Medicina. Divisão de Biblioteca e Documentação. Guia de apresentação de dissertações, teses e monografias. Elaborado por Anneliese Carneiro da Cunha, Maria Julia de A. L. Freddi, Maria F. Crestana, Marinalva de Souza Aragão, Suely Campos Cardoso, Valéria Vilhena. 3a ed. São Paulo: Divisão de Biblioteca e Documentação; 2011.

Abreviaturas dos títulos dos periódicos de acordo com List of Journals Indexed in Index Medicus. 


\section{SUMÁRIO}

LISTA DE FIGURAS

LISTA DE TABELAS

LISTA DE ABREVIATURAS

RESUMO

ABSTRACT

1.INTRODUÇÃO

2.OBJETIVOS

2.1. Objetivo específico

2.2. Objetivos gerais

3.MATERIAL E MÉTODO

3.1. Tratamento de aterosclerose induzida em coelhos

3.2. Preparo da dieta rica em colesterol

3.3. Determinações bioquímicas e hematológicas 
3.4. Síntese do derivado N-oleil-daunorrubicina (ODNR) e incorporação na 11 nanopartícula lipídica rica em colesterol (LDE)

3.5. Ecocardiograma

3.6. Análise da planimetria macroscópica

3.7. Análise da planimetria microscópica

3.8. Imunohistoquímica

3.9. Expressão proteica por Western blot

3.10. Expressão gênica por PCR quantitativo em tempo real (qRT-PCR)

4. RESULTADOS

4.1. Massa Corporal

4.2. Análise do consumo de ração

4.3. Avaliação do perfil hematológico

4.5. Análise macroscópica

4.9. Análise da expressão proteica por Western blot e expressão gênica por qRT-PCR 
4.9.1. Processo Inflamatório

4.9.3. MMPs

32

4.9.4. Morte Celular

5. DISCUSSÃO

6. CONCLUSÃO 


\section{LISTA DE FIGURAS}

Figura 1: Reação de obtenção do derivado ODNR a partir da DNR e do ácido oléico na presença de DCC e 4-DMAP a temperatura ambiente

Figura 2: Massa corporal semanal em $\mathrm{Kg}$ dos grupos LDE e LDE-DNR. 18 Valores expressos em Média EPM.

Figura 3: Consumo semanal de ração com 1\% de colesterol dos grupos 19 LDE e LDE-DNR. Valores expressos em Média土 EPM.

Figura 4: Fotos representativas das aortas dos coelhos dos grupos LDE 23 e LDE-DNR.

Figura 5: (A) Razão da área da íntima e média do arco aórtico dos 24 coelhos dos grupos LDE e LDE-DNR. (B) Imagem representativa de corte histológico do arco aórtico dos coelhos dos grupos LDE e LDEDNR. Coloração de hematoxilina e eosina. Aumento de 100x.

Figura 6: (A) Porcentagem do marcador Ki-67 em núcleo com 26 proliferação celular nos grupos LDE $(n=7)$ e LDE-DNR (n=9) (B) Imagens representativas de núcleos marcados positivamente com Ki-67 (núcleos marrons), e negativamente (núcleos azuis).

Figura 7: (A) Imagem representativa de bandas de Western blot para as proteínas CD68, TNF-a e IL-6. (B) Expressão proteica de CD68 na aorta ascendente dos coelhos dos grupos $\operatorname{LDE}(n=3)$ e LDE-DNR $(n=4)$. (C) Imagens representativas de imunohistoquímica para macrófagos no arco aórtico marcado com cromógeno DAB nos grupos LDE e LDE-DNR. (D) Expressão proteica de TNF- $\alpha$ na aorta ascendente dos coelhos dos grupos LDE $(n=3)$ e LDE-DNR $(n=4)$. (E) Expressão proteica de IL-6 na 
aorta ascendente dos coelhos dos grupos LDE ( $n=3)$ e LDE-DNR $(n=4)$.

Figura 8: (A) Expressão gênica de MCP-1 na aorta ascendente dos coelhos dos grupos LDE $(n=6)$ e LDE-DNR $(n=6)$. (B) Expressão gênica de IL-18 na aorta ascendente dos coelhos dos grupos LDE $(n=6)$ e LDEDNR $(n=6)$. (C) Expressão gênica de IL-10 na aorta ascendente dos coelhos dos grupos LDE $(n=6)$ e LDE-DNR ( $n=6)$. (D) Expressão gênica de IL-1 $\beta$ na aorta ascendente dos coelhos dos grupos LDE $(n=6)$ e LDE$\operatorname{DNR}(n=6)$.

Figura 9: (A) Expressão gênica de MCP-1 no tecido cardíaco dos coelhos dos grupos LDE $(n=6)$ e LDE-DNR $(n=6)$. (B) Expressão gênica de IL-18 no tecido cardíaco dos coelhos dos grupos LDE $(n=6)$ e LDE-DNR $(n=6)$. (C) Expressão gênica de IL-10 no tecido cardíaco dos coelhos dos grupos LDE $(n=6)$ e LDE-DNR $(n=6)$. (D) Expressão gênica de IL-1 $\beta$ no tecido cardíaco dos coelhos dos grupos LDE ( $n=6)$ e LDE-DNR $(n=6)$.

Figura 10: (A) Imagem representativa de bandas de Western blot para a proteína VCAM-1. (B) Expressão proteica de VCAM-1 na aorta 31 ascendente dos coelhos dos grupos LDE $(n=3)$ e LDE-DNR $(n=4)$. (C) Expressão gênica de VCAM-1 na aorta ascendente dos coelhos dos grupos LDE $(n=6)$ e LDE-DNR $(n=6)$.

Figura 11: Expressão gênica de VCAM-1 no tecido cardíaco dos coelhos dos grupos LDE $(n=6)$ e LDE-DNR $(n=6)$.

Figura 12: (A) Imagem representativa de bandas de Western blot para as proteínas MMP-2 e MMP-9. (B) Expressão proteica de MMP-2 na aorta 32 ascendente dos coelhos dos grupos LDE $(n=3)$ e LDE-DNR $(n=4)$. (C) Expressão proteica de MMP-9 na aorta ascendente dos coelhos dos grupos LDE $(n=3)$ e LDE-DNR $(n=4)$. (D) Expressão gênica de MMP-12 na aorta ascendente dos coelhos dos grupos LDE $(n=6)$ e LDE-DNR $(n=6)$. 
Figura 13: (A) Imagem representativa de bandas de Western blot para as proteínas Caspases 3 e 9 e BAX. (B) Expressão proteica de caspase 3 em aorta ascendente dos coelhos dos grupos LDE $(n=3)$ e LDE-DNR $(n=4)$. (C) Expressão proteica de Caspase 9 na aorta ascendente dos coelhos dos grupos LDE $(n=3)$ e LDE-DNR $(n=4)$. (D) Expressão proteica de Bax na aorta ascendente dos coelhos dos grupos LDE ( $n=3)$ e LDE$\operatorname{DNR}(n=4)$.

Figura 14: (A) Imagem representativa de bandas de Western blot para a proteína VEGF. (B) Expressão proteica de VEGF em arco aórtico dos coelhos dos grupos LDE ( $n=3)$ e LDE-DNR $(n=4)$. 


\section{LISTA DE TABELAS}

Tabela 1: Perfil hematológico dos grupos LDE $(n=7)$ e LDE-DNR $(n=9) \quad 19$ nos períodos basal, pré-tratamento e pós-tratamento.

Tabela 2: Perfil bioquímico dos grupos LDE $(n=7)$ e LDE-DNR ( $n=9)$ nos 21 períodos basal, pré-tratamento e pós-tratamento.

Tabela 3: Análise macroscópica da área das aortas, área de lesão, e 24 porcentagem da lesão dos grupos LDE $(n=7)$ e LDE-DNR $(n=9)$.

Tabela 4: Análise ecocardiográfica de grupos de coelhos saudáveis 25 (Controle) $(n=3)$, LDE $(n=7)$ e LDE-DNR $(n=9)$. 


\section{LISTA DE ABREVIATURAS}

ALT - Aspartato aminotransferase

ANVISA - Agência Nacional de Vigilância Sanitária

Apos - Apolipoproteínas

AST - Alanina Aminotransferase

DAB - Diaminibenzidina

DCC - N,N'-Diciclohexilcarbodiimida

DD - Diâmetro final do ventrículo esquerdo Diastólico

4-DMAP - N, N-dimetilpiridin-4-amina

DNR - Daunorrubicina

DS - Diâmetro final do ventrículo esquerdo Sistólico

EPM - Erro Padrão da Média

FDA - Food and Drug Administration

FE - Fração de Ejeção

Fen - Fração de Encurtamento

HDL - Lipoproteína de alta densidade

HPLC - Cromatografia líquida de alta eficiência

LDL - Lipoproteína de baixa densidade

LMA - Leucemia Mieloide Aguda

MCP-1 - Quimioatraente de monócitos 1

MMPs - Metaloproteináses

mVE - massa do Ventrículo Esquerdo 
$\mathrm{NaOH}$ - hidróxido de sódio

ODNR - N-oleil-daunorrubicina

PBS - Salina tamponada com sais de fosfato

PP - Parede Posterior

PTX - Paclitaxel

SIV - Espessura da parede do Septo Interventricular

TD - Tempo de Desaceleração

Top2 - Topoisomerase 2

TRIV - Tempo de Relaxamento Isovolumétrico

VCAM-1 - Adesão celular vascular

VDF - Volume do ventrículo esquerdo Diastólico

VLDL - Lipoproteína de muito baixa densidade

VSF - Volume do ventrículo esquerdo Diastólico 


\section{RESUMO}

ALBUQUERQUE C.I. Uso do quimioterápico daunorrubicina associado à nanoemulsões lipídicas no tratamento da aterosclerose experimental em coelho. [Tese]. São Paulo: Faculdade de Medicina, Universidade de São Paulo; 2021.

As nanopartículas lipídicas (LDE) demonstraram eficácia como veículo de direcionamento de fármacos no tratamento de aterosclerose e câncer em pacientes e em modelo animal. A LDE é sintetizada em laboratório com estrutura e composição semelhantes à LDL e concentra-se em locais com altas taxas de proliferação celular, como nas lesões ateroscleróticas. O agente quimioterápico daunorrubicina (DNR) é antiproliferativo e citotóxico e em estudos anteriores foi associada a LDE em modelo de câncer murino, não apresentando toxicidade relevante. Coelhos New Zealand machos foram submetidos a uma dieta com colesterol $1 \%$ durante 8 semanas. Após 4 semanas do início da dieta, os animais foram divididos em: Grupo LDE-DNR (6mg/kg EV, $\mathrm{n}=9$ ), tratados semanalmente com DNR associada à LDE; Grupo LDE (EV, $n=7)$, tratados com apenas LDE. Além disso, foi utilizado um grupo Controle de 3 animais, os quais não foram submetidos a qualquer intervenção. Perfil lipídico e hematológico, consumo de ração, massa corporal e ecocardiograma foram avaliados antes do início da dieta rica em colesterol, no pré-tratamento e pós-tratamento. Morfometria e Western blot foram realizados em segmentos das aortas, qRT-PCR foi realizado em segmento da aorta e tecido cardíaco. No grupo LDE-DNR as lesões macroscópicas aórticas foram $50 \%$ menores. A expressão proteica dos marcadores relacionados à inflamação CD68, IL-6 e TNF- $\alpha$ foi menor no grupo LDE-DNR em relação ao grupo LDE. Fatores pró-apoptóticos BAX, caspase 3 e caspase 9 também foram menores em LDE-DNR quando comparado ao grupo LDE. A expressão proteica do fator de crescimento endotelial (VEGF) e da molécula de adesão celular vascular (VCAM) foi menor no grupo LDE-DNR quando comparado ao grupo LDE. As interleucinas (IL-18, IL-10 e IL-1 $\beta$ ) não tiveram diferença na expressão gênica quando comparado os grupos LDE-DNR e LDE. Entretanto, expressão gênica dos marcadores MMP12, MCP-1 e VCAM-1 foram menores no grupo LDE-DNR quando comparado ao grupo LDE. Pela ecocardiografia observou-se nos grupos LDE e LDE-DNR que as funções sistólica e diastólica foram preservadas comparadas ao grupo controle e não houve diferença na massa cardíaca entre os 3 grupos. Os grupos estudados não apresentaram diferenças na ingestão de ração e peso corporal, e a LDE-DNR não apresentou toxicidade observável no hemograma, porém houve um aumento na enzima hepática AST no grupo LDEDNR que começou no período de pré-tratamento e continuou até o fim do protocolo. O tratamento com LDE-DNR reduziu a inflamação e a morte celular na aorta além de não prejudicar a função cardíaca desses animais, e reduzir drasticamente as lesões ateroscleróticas do grupo tratado com a associação.

Descritores: Aterosclerose, nanopartículas, daunorrubicina, inflamação, coelhos, quimioterápicos. 


\begin{abstract}
ALBUQUERQUE C.I. Use of the chemotherapy drug daunorubicin associated with lipid nanoemulsions in the treatment of experimental atherosclerosis in rabbits. [Thesis]. São Paulo: Faculty of Medicine, University of São Paulo; 2021.
\end{abstract}

Lipid nanoparticles (LDE) have shown effectiveness as a vehicle for targeting chemotherapeutic drugs in treatment of atherosclerosis and cancer in patients and in animal model. LDE was synthesized in laboratory with a structure and composition similar to LDL and it is concentrated in places with high rates of cell proliferation, such as atherosclerotic lesions. Daunorubicin (DNR) is a chemotherapy drug that in previous studies has been associated with LDE to treat a murine cancer model, with no relevant toxicity. Male New Zealand rabbits were fed with $1 \%$ cholesterol diet for 8 weeks. After 4 weeks from the beginning of the diet, the animals were divided in three groups: LDE-DNR group (6mg/kg iv, $n=9)$, treated weekly with DNR associated with LDE; LDE group (iv, $n=7$ ), treated with LDE only, and Control group (3 animals) that no intervention was performed. Lipid and hematological profile, chow consumption, body mass and echocardiography were evaluated in the baseline, pre-treatment and post-treatment periods. Morphometry, protein and gene expression were performed on segments of the aortas. Aortic lesions were $50 \%$ smaller in LDE-DNR group compared to the LDE group. Protein expression of markers related to inflammation CD68, IL-6 and TNF$\alpha$ were lower in the LDE-DNR group compared to the LDE group. Pro-apoptotic factors BAX, caspase 3 and caspase 9 were also lower in LDE-DNR when compared to the LDE group. Protein expression of VEGF and VCAM were lower in LDE-DNR group when compared to LDE group. In addition, gene expression of MMP12, VCAM-1 and MCP-1 were lower in LDE-DNR group when compared to LDE group. The gene expression of interleukins (IL-18, IL-10 e IL-1 $\beta$ ) had no difference when compared LDE-DNR and LDE group. By echocardiography, it was observed in LDE and LDE-DNR groups that the systolic and diastolic functions were preserved and there was no difference in cardiac mass between the 3 groups. There was no difference in chow consumption and body weight, and the LDE-DNR did not show toxicity that could be observed in blood count, however, there was an increase in levels of liver enzyme AST in LDE-DNR group that started in pre-treatment period and continued until the end of the protocol. Treatment with LDE-DNR reduced inflammation and cell death in aorta and did not impair cardiac function of these animals. In addition, remarkably reduced atherosclerotic lesions.

Descriptors: Atherosclerosis, nanoparticles, daunorubicin, inflammation, rabbits, chemotherapy. 


\section{INTRODUÇÃO}

As doenças cardiovasculares são as principais causas de óbitos no mundo (Sánchez-Roa et al., 2020). Cerca de 17,9 milhões de indivíduos são vítimas fatais destas doenças a cada ano, sendo que $75 \%$ dessas mortes ocorrem em países em desenvolvimento e um terço desses óbitos acontece em pessoas com menos de 70 anos (RUAN et al., 2018). No Brasil a principal causa de doenças cardiovasculares é a aterosclerose cujos principais fatores de risco para a formação dessas lesões fibróticas na parede arterial são hipercolesterolemia, hipertensão arterial, diabetes mellitus, hipertensão ou mediadores próinflamatórios (CHACRA et al., 2019).

A aterosclerose é considerada uma doença inflamatória crônica caracterizada por intensa atividade imunológica. O processo aterogênico começa por alterações no endotélio vascular ao expressarem moléculas de adesão como a proteína de adesão celular vascular (VCAM-1) e quimiocinas como a proteína quimioatraente de monócitos 1 (MCP-1) que capturam leucócitos nas suas superfícies. As mudanças na permeabilidade endotelial e a composição da matriz extracelular sob o endotélio promovem a entrada e retenção do colesterol contendo partículas de lipoproteínas de baixa densidade (LDL) na parede da artéria (LIBBY et al., 2019). Essas partículas de LDL acumuladas podem sofrer oxidação na região subendotelial visto que estão vulneráveis a ação de enzimas como metaloproteinases (MMPs), lipoxigenases e espécies reativas de oxigênio. Essas LDL oxidadas estimulam a entrada de monócitos na parede arterial (SANDA et al., 2017).

Uma vez aderentes ao endotélio, os monócitos e linfócitos migram para a camada mais interna da artéria, a camada íntima, em resposta a estímulos quimioatraentes. Assim que estão localizados na parede da artéria, os monócitos diferenciam-se em macrófagos (HANSSON et al., 2006). A ativação de macrófagos no ateroma leva à liberação de moléculas vasoativas como óxido nítrico, endotelinas, eicosanóides e espécies reativas de oxigênio. Esses macrófagos captam a LDL oxidada, porém essa internalização leva à formação de peróxidos lipídicos e facilita o acúmulo de ésteres de colesterol resultando na formação de células espumosas (RUNHUA et al., 2019). 
O macrófago ativado, abundante no ateroma, produz enzimas proteolíticas capazes de degradar colágeno como as MMPs, e fatores tissulares responsáveis pelo desencadeamento da quebra de matriz extracelular e pela formação da placa aterosclerótica (LUNDE et al., 2019). A longo prazo, as lesões se desenvolvem e se tornam mais complexas, apresentando apoptose e necrose dos macrófagos e das células do músculo liso no núcleo da lesão. Uma capa fibrosa se forma ao redor e se torna mais espessa ao longo do desenvolvimento da placa. O crescimento da placa provoca o estreitamento do lúmen arterial por formação de trombos, demonstrando uma ligação essencial entre a inflamação arterial e a trombose (DE GAETANO et al., 2016).

As placas ateroscleróticas podem tornar-se cada vez mais complexas, com calcificação, ulceração na superfície luminal e hemorragia de pequenos vasos que crescem na lesão a partir da camada média dos vasos sanguíneos. A propagação das lesões na aterosclerose conduz à angiogênese na parede da artéria, semelhante ao observado no crescimento de tumores cancerosos (PEÑA et al., 2017; YAO et al., 2019).

O tratamento da aterosclerose tem avançado nos últimos anos, porém os medicamentos mais utilizados estão focados em tratar os fatores de risco, como medicamentos anti-hipertensivos, estatinas e anticoagulantes. Estes fármacos podem causar efeitos colaterais no rim e no fígado quando utilizados a longo prazo (LIU et al., 2019). Além disso, o uso dos stents e stents farmacológicos podem gerar reestenose e trombose além de não reduzirem expressivamente as taxas de mortalidade desses pacientes (ALFONSO et al., 2012; AL-GOBARI et al., 2017). Sendo assim, existe uma necessidade de procurar novas propostas de tratamento que ajam diretamente na lesão aterosclerótica e com menos efeitos adversos.

Uma possível alternativa seria o tratamento com fármacos antiproliferativos ou anti-inflamatórios, por apresentarem maior eficiência e agir na fisiopatogenia da doença, porém por ser um tratamento sistêmico os efeitos colaterais desses fármacos constituem grande limitação. Por isso, concentrar os fármacos no sítio de ação ("drug-targeting"), diminuiria a captação por outros tecidos e órgãos. O uso desses sistemas de transporte direcionado pode levar à maior eficiência dos 
fármacos já em uso, evitando os elevados custos envolvidos no desenvolvimento de novos agentes. (BULGARELLI et al., 2013).

Maranhão et al., (1992) desenvolveram nanopartículas lipídicas capazes de concentrar-se em tecidos-alvo, como os tumores malignos e sítios de inflamação e com isso carreou quimioterápicos dirigidos a essas células. Foi a primeira vez que se demonstrou o direcionamento de partículas sólidas artificiais para o sítio de ação, e essa nanopartícula foi nomeada LDE (MARANHÃO et al., 1993; 1994).

As nanopartículas são produzidas sem proteína, por meio de tecnologias baseadas em ultrassom ou microfluidização sob alta pressão. A estrutura e composição lipídica das nanopartículas, são semelhantes a LDL. Isto permite que, em contato com a corrente sanguínea, adquiram várias apolipoproteínas (apos) presentes nas lipoproteínas plasmáticas. Uma dessas apos, a apo E, é reconhecida pelos receptores da LDL e isto permite que a nanopartícula seja captada pelas células pelo mesmo processo de captação da LDL (MARANHÃO et al., 1993;1997).

A expressão dos receptores da LDL aumenta acentuadamente nas células neoplásicas (HO et al., 1978). Este fenômeno é decorrente da aceleração da mitose das células neoplásicas que demanda lípides para atender à síntese de novas membranas exigida pela duplicação celular. Isto resulta em captação aumentada da LDL nativa e da LDE por essas células. Os fármacos de ação terapêutica, ao serem associados à LDE, são captados junto com as nanopartículas após injeção na corrente circulatória e concentram-se assim no tecido-alvo, como os tumores malignos (ADES et al., 2001). Trata-se de um fenômeno de grande intensidade. Em pacientes com carcinoma de mama (GRAZIANI et al., 2002) e ovário (ADES et al., 2001), houve captação da LDE de 5 e 10 vezes maior do que o tecido normal correspondente, respectivamente. Em estudos de cinética plasmática em pacientes com leucemia mieloide aguda (LMA), foi estimado que a absorção da LDE em células de LMA foi cerca de $66 \%$ e apenas $34 \%$ da LDE foi absorvida pelos tecidos normais (MARANHÃO et al., 1994). 
O uso de nanopartículas como veículo de fármacos deve abordar questões complexas como capacidade de carregamento de drogas, perfil de liberação desejado, estabilidade da dispersão aquosa e biocompatibilidade com células e tecidos, para evitar a dissociação rápida da droga no sistema transportador e aumentar a sua eficácia terapêutica no tecido alvo. Para evitar essa dissociação, o fármaco pode ser modificado para aumentar a sua lipofilicidade e afinidade pela nanopartícula (JAIN et al., 2005; WANG et al., 2011; ZHANG, 2014).

Em nosso laboratório foram desenvolvidas seis formulações de quimioterápicos associados à LDE: carmustina (MARANHÃO et al., 2002), os derivados de paclitaxel (RODRIGUES et al., 2002; 2005), etoposídeo (VALDUGA et al., 2003), daunorrubicina (DNR) (TEIXEIRA et al., 2008), metotrexato (MOURA et al., 2011) e de docetaxel (MENEGHINI et al., 2019). A estratégia adotada para derivatizar esses cinco últimos quimioterápicos para associá-los à LDE visaram adicionar um ácido graxo à estrutura molecular do fármaco aumentando a estabilidade dessa associação.

Em cultura celular (RODRIGUES et al., 2002; VALDUGA et al., 2003), em estudos de farmacocinética em animais (RODRIGUES et al., 2005) e em pacientes (MARANHÃO et al., 2002), mostrou-se que as diversas preparações de LDE-quimioterápicos eram estáveis. Esses estudos demonstraram que o fármaco transportado pelas nanopartículas não se dissocia delas na circulação, permanecendo na LDE até a entrada nas células, o que é indispensável para obtenção do efeito "drug-targeting".

Testes clínicos em pacientes com neoplasias malignas avançadas e resistentes a múltiplos fármacos mostraram a segurança das preparações e confirmaram a capacidade da LDE de neutralizar a toxicidade e efeitos mielossupressores desses fármacos (MARANHÃO et al., 2002). Estas toxicidades que trazem risco de óbito e limitam muito o tratamento quimioterápico foram praticamente eliminados pela veiculação por LDE, mesmo com a administração dos fármacos em altas doses (GRAZIANI et al., 2017).

O processo de veiculação da DNR à LDE foi testado in vitro e in vivo, e com base nos parâmetros de farmacologia, como a determinação de doses letais, foi 
visto que esta associação reduz drasticamente a toxicidade desse quimioterápico (DORLHIAC-LLACER et al., 2001; TEIXEIRA et al., 2008; CONTENTE et al., 2014).

A DNR faz parte de uma família de antibióticos antraciclínicos que são considerados muito eficazes no tratamento de vários tipos de câncer, os principais fármacos dessa família aprovados pelo FDA (Food and Drug Administration) nos Estados Unidos e pela ANVISA (Agência Nacional de Vigilância Sanitária) no Brasil são: DNR, doxorrubicina, epirrubicina e idarrubicina. (ROBERT, 1988, LOTFI et al., 2002; SALVATORELLI et al., 2018). Esses antibióticos são amplamente utilizados na oncologia clínica, porém o seu uso é limitado por causar mielossupressão e cardiotoxicidade nos pacientes (HOFLAND et al., 2005; SRANKOVA et al., 2019).

A família desses fármacos se originou na década de 1950 quando a DNR foi o primeiro antibiótico isolado da cultura de Streptomyces peucetius, e na década de 1960 se descobriu a eficácia deste fármaco no tratamento de leucemia linfoide aguda e leucemia mieloide (DUBEY et al., 2014). As antraciclinas apresentam núcleos quinônicos que permitem a sua participação em reações de transferência eletrônica para gerar radicais livres que danificam a célula alvo (SHADLE et al., 2000). Estes grupos de fármacos são metabolizados no fígado e excretados principalmente pela bile. Apesar de uma pequena fração ser eliminada pela urina, a maior parte da dose administrada, aproximadamente $50 \%$, é removida do organismo sem metabolização. Em modelo experimental com ratos, foi estimado que $22 \%$ da dose injetada sofre reciclagem entero-hepática (ROBERT et al., 1992; SZWED et al., 2014).

O mecanismo de ação anti-proliferativo das antraciclinas consiste na formação de um complexo ternário Top2-antraciclina-DNA que inibe a atividade da topoisomerase 2 (top2) (SILBER et al., 1987; SWIFT et al., 2008). Existem duas isoenzimas top2 nas células de mamíferos, a Top2 $\alpha$ e a Top2 $\beta$. (JENKINS et al., 1992). Entretanto as duas isoenzimas diferem em seu perfil de expressão celular.

A Top2a é regulada pelo ciclo celular e é expressa em células em proliferação normais e tumorais (SAPETTO-REBOW et al., 2011). A expressão da 
Top2 $\beta$ não é regulada pelo ciclo celular, mas pode ser encontrada em todas as células de mamíferos ao longo do ciclo celular e a expressão predominante pode ser vista somente em células que atingiram o estado pós mitótico (LYU et al., 2007). A eficácia do tratamento com as antraciclinas provavelmente está ligada à expressão altamente elevada da Top2 $\alpha$ em células tumorais (CAPRANICO et al., 1992), e o mecanismo exato da cardiotoxicidade induzida pelas antraciclinas ainda não está claro, porém se sabe que a Top2 $\beta$ está presente em células quiescentes, como cardiomiócitos adultos de mamíferos e sua expressão permanece constante ao longo do ciclo celular (MAILLET et al., 2016).

A aterosclerose e o câncer são doenças crônicas multifatoriais que compartilham não apenas várias vias moleculares importantes, mas também muitos processos etiológicos e mecanísticos desde os estágios iniciais do desenvolvimento até as formas avançadas em ambas as patologias. Fatores envolvidos em sua progressão compreendem alterações genéticas, processos inflamatórios, aumento de proliferação celular e estresse oxidativo, como os mais importantes (LAGARES et al., 2017).

Naoum et al., (2004) reportou que a LDE também pode ser captada mais intensamente por tecidos não-neoplásicos de proliferação rápida, como acontece em pacientes com talassemia minor. Com base nesta informação, Couto et al., (2007), injetaram a LDE radioativa em pacientes com doença arterial coronária e verificaram que as nanopartículas se concentravam nas lesões ateroscleróticas do mesmo modo que a LDL nativa, abrangendo assim, o uso da LDE para possíveis tratamentos cardiovasculares. Além disso, Maranhão et al., (2008) injetaram LDE radioativa em coelhos com aterosclerose e demonstraram que a captação da LDE nas aortas de coelhos alimentados com dieta rica em colesterol foi duas vezes maior do que em coelhos que se alimentavam com ração normal.

Sendo assim, Maranhão et al., (2008) associaram a nanopartícula LDE ao paclitaxel, iniciando os tratamentos com quimioterápicos em coelhos com aterosclerose. Outros quimioterápicos associados à LDE também foram estudados no tratamento de coelhos com aterosclerose como o etoposídeo (TAVARES et al., 2011), metotrexato (BULGARELLI et al., 2013), carmustina (DAMINELLI et al., 2016) e docetaxel (MENEGHINI et al., 2019) e todas as associações reduziram as 
áreas de lesões ateroscleróticas e diminuíram suas toxicidades no tratamento experimental em coelhos.

Devido ao tratamento experimental de LDE-paclitaxel (LDE-PTX) em coelhos ter tido bons resultados, esta associação também foi utilizada em pacientes com aterosclerose aórtica que foram tratados com LDE-PTX e foram comparados a um grupo controle que não receberam tratamento. A LDE-PTX não resultou em toxicidade clínica ou laboratorial, evidenciando a segurança do tratamento da aterosclerose com um agente antineoplásico de alta toxicidade. Além disso, houve redução no volume médio das placas ateroscleróticas em $50 \%$ dos pacientes tratados. Como esperado, não houve alteração no volume das placas de pacientes do grupo controle. Estes resultados comprovaram a tolerabilidade do LDE-PTX e o seu potencial uso para a redução da lesão aterosclerótica (SHIOZAKI et al., 2016).

A DNR associada à LDE foi estudada por Teixeira et al., (2008) que sintetizaram um derivado de DNR, o oleato de DNR e incorporaram à nanopartícula. A preparação revelou-se estável, com incorporação quase completa da DNR à LDE, e houve uma redução acentuada da cardiotoxicidade, toxicidade e citotoxicidade quando comparada à DNR comercial.

Contente et al., (2014) estudaram a dose máxima tolerada e encontraram que a LDE-DNR foi 65 vezes maior do que a da DNR comercial, indicando uma grande redução da toxicidade do fármaco. Além disso, a capacidade da LDE-DNR de inibir o crescimento tumoral, no modelo de melanoma metastático implantado em camundongos foi duas vezes maior do que a da DNR comercial.

Devido a esta redução da toxicidade, e principalmente da cardiotoxicidade observada no tratamento com a formulação LDE-DNR no modelo de tumor murino nos fizeram levantar a hipótese de que esta preparação possa também, ter ação anti-aterosclerótica importante com toxicidade muito baixa. As preparações de LDE como veículo carreador de paclitaxel, docetaxel, etoposídeo e metotrexato mostraram claramente esta possibilidade. Por esse motivo, planejamos testar o uso da DNR associada à nanopartícula LDE em coelhos com aterosclerose experimental, com a expectativa de reduzir a proliferação celular aumentada na 
aorta destes animais. Dessa forma, teríamos uma nova e poderosa arma no arsenal terapêutico das doenças cardiovasculares de natureza aterosclerótica. 


\section{OBJETIVOS}

\subsection{Objetivo geral}

Investigar a eficácia do uso da DNR associada à LDE no tratamento da aterosclerose induzida por dieta rica em colesterol em coelhos.

\subsection{Objetivos específicos}

Quantificar as expressões proteicas e gênicas dos marcadores envolvidos nos processos de inflamação e morte celular nas aortas dos coelhos.

Avaliar se a associação de LDE-DNR causa toxicidade hematológica, renal, hepática e cardíaca no tratamento de coelhos com aterosclerose. 


\section{MATERIAL E MÉTODO}

\subsection{Tratamento de aterosclerose induzida em coelhos}

Foram utilizados 16 coelhos brancos da raça New Zealand, pesando aproximadamente $3 \mathrm{Kg}$, foram acondicionados em gaiolas individuais em sala com temperatura controlada $\left(20-22^{\circ} \mathrm{C}\right)$ e sob ciclo de claro/escuro de 12 horas no biotério da Divisão Experimental do Instituto do Coração do Hospital das Clínicas da Universidade de São Paulo. A água foi fornecida à vontade.

Inicialmente os coelhos consumiram ração comercial usual (Purina Inc.) constituída de $16 \%$ de proteínas, $7 \%$ de lipídeos, $14 \%$ de fibra bruta, $7 \%$ de cinzas e $50 \%$ de extrato não nitrogenado por uma semana para adaptação às condições ambientais do biotério.

Após a primeira semana, todos os coelhos foram submetidos a uma dieta rica em colesterol durante 8 semanas (150 gramas de ração/dia enriquecida com $1 \%$ de colesterol). Após 4 semanas do início da administração da dieta rica em colesterol, os coelhos foram divididos em 2 grupos, sendo 7 animais no grupo LDE e 9 no grupo LDE-DNR, de acordo com o tratamento administrado:

1- Grupo $\operatorname{LDE}(n=7)$ : recebeu uma injeção endovenosa, contendo a nanopartícula LDE sem o fármaco, o volume de LDE administrado foi equivalente ao volume injetado nos animais que receberam LDE-DNR.

2- $\quad$ Grupo LDE-DNR ( $\mathrm{n}=9$ ): foi tratado com uma dose de $6 \mathrm{mg} / \mathrm{kg}$ de DNR associada à nanopartícula LDE.

3- Grupo Controle $(n=3)$ : receberam ração normal sem adição de colesterol, foi utilizado somente no estudo ecocardiográfico como controle para os dois grupos alimentados com colesterol, LDE e LDE-DNR.

Todos os tratamentos foram administrados uma vez por semana, pelo período de 4 semanas. Os animais foram pesados semanalmente para a avaliação do peso corporal. O consumo de ração foi avaliado diariamente, pesando-se o resíduo de ração. Após a finalização do tratamento, os animais foram sacrificados com injeção endovenosa de uma dose letal de tiopental sódico. 
As aortas dos animais de ambos os grupos foram armazenadas para análises de planimetria, histologia, imunohistoquímica, Western blot, e RT-PCR.

\subsection{Preparo da dieta rica em colesterol}

A dieta rica em colesterol foi preparada através da vaporização de uma solução de colesterol, éter etílico e etanol absoluto sobre a ração comercial usual, na proporção de $1 \mathrm{~g}$ de colesterol para $100 \mathrm{~g}$ de ração. O colesterol foi solubilizado adicionando-se $100 \mathrm{ml}$ de éter etílico e $50 \mathrm{ml}$ de álcool absoluto para 10 gramas de colesterol sob agitação. Após a adição da solução, a ração permaneceu em repouso por 24 horas em câmara de fluxo laminar para a evaporação completa dos solventes. A ração rica em colesterol foi pesada e separada em porções individuais de $150 \mathrm{~g}$ em sacos plásticos lacrados e armazenados a $-20^{\circ} \mathrm{C}$.

\subsection{Determinações bioquímicas e hematológicas}

As análises das alterações no perfil hematológico e bioquímico foram realizadas pelo Laboratório de Análises Especiais - LIM03 da Faculdade de Medicina da Universidade de São Paulo antes do início da dieta, e antes do início e após o final do tratamento em todos os animais. As amostras de sangue dos coelhos foram coletadas da veia auricular marginal e centrifugadas a $2500 \mathrm{rpm}$ por 10 minutos a $4{ }^{\circ} \mathrm{C}$ para a separação do soro. Os perfis bioquímicos análisados foram triglicérides, colesterol total, HDL, LDL, VLDL, aspartato aminotransferase $(\mathrm{ALT})$, alanina aminotransferase (AST), fosfatase alcalina, Uréia, Creatinina, Bilirrubina total e frações.

\subsection{Síntese do derivado $\mathrm{N}$-oleil-daunorrubicina (ODNR) e incorporação} na nanopartícula lipídica rica em colesterol (LDE)

A apresentação comercial da DNR (MedKoo Biosciences, Inc.; Carolina do Norte, EUA), composta por cloridrato de DNR, foi solubilizada em água e solução de hidróxido de sódio $(\mathrm{NaOH})$ 1M. Em seguida, a DNR livre foi extraída com clorofórmio e concentrada em rotaevaporador.

A síntese para reação de derivatização da ODNR utilizou DNR livre, ácido
oleico,
4-DMAP
$(\mathrm{N}, \quad \mathrm{N}$-dimetilpiridin-4-amina)
e DCC
$\left(\mathrm{N}, \mathrm{N}^{\prime}-\right.$ 
Diciclohexilcarbodiimida). A reação permaneceu sob agitação e atmosfera de $\mathrm{N}_{2}$ por 2 horas à temperatura ambiente. A reação foi monitorada por cromatografia líquida de alta eficiência (HPLC). Após a formação do produto, concentrou-se a fase orgânica em rotaevaporador. Após a eliminação dos resíduos da reação por extrações líquido-líquido com éter etílico e água, e clorofórmio e água, a fase orgânica foi lavada com solução saturada de tiossulfato de sódio, filtrada na presença de sulfato de sódio e seca em rotaevaporador.

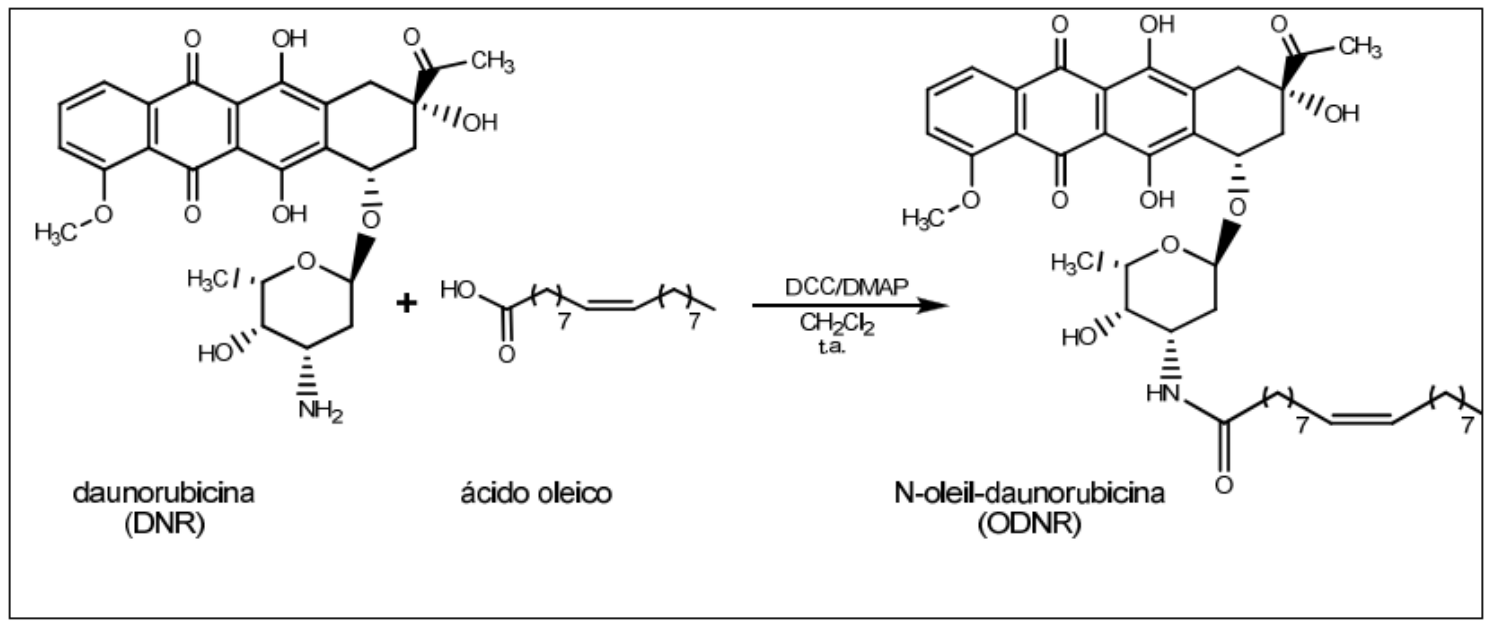

Figura 1: Reação de obtenção do derivado ODNR a partir da DNR e do ácido oléico na presença de DCC e 4-DMAP a temperatura ambiente.

A técnica de preparo utilizada foi a descrita por Maranhão et al., (1993). Para o preparo da nanopartícula ou da LDE-ODNR, utilizou-se uma mistura desses lipídios que contém: $333 \mathrm{mg}$ de fosfatidilcolina de ovo, $135 \mathrm{mg}$ éster de colesterol, $6 \mathrm{mg}$ de colesterol livre, $132 \mathrm{mg}$ de migliol (grau de pureza $\geq 99 \%$ ). Em seguida, a mistura de lípides foi seca sob fluxo de nitrogênio e mantida em dessecador a vácuo por 12 horas a $4 \stackrel{\circ}{\circ}$. Após a adição de polissorbato e $10 \mathrm{~mL}$ de solução tampão Tris - $\mathrm{HCl} 0,01 \mathrm{M}$, pH 8,05 a mistura de lipídios foi préemulsificada por irradiação ultrassônica e emulsificada em homogeneizador de alta pressão Emulsiflex C5. Para o preparo da LDE-ODNR, acrescentou-se à mistura de lípides o ODNR na proporção de 1:10 fármaco:lípides. Ao término dos ciclos de homogeneização a emulsão formada foi centrifugada a 3700 rpm, por 20 minutos e esterilizada por filtração em membrana Millipore $(0,22 \mu \mathrm{m})$ em fluxo laminar. A taxa de associação do fármaco à LDE foi analisada por HPLC e a preparação foi armazenada em frascos estéreis a $4^{\circ} \mathrm{C}$. 


\subsection{Ecocardiografia}

As análises do estudo ecocardiográfico dos coelhos foram realizadas ao final do protocolo nos grupos LDE e LDE-DNR. Somente para o estudo ecográfico foi adicionado um grupo de coelhos saudáveis $(n=3)$ que recebeu a dieta comercial sem a adição de colesterol.

O sistema de ultrassom (Vivid 7 - GE Horton, Norway) foi utilizado para a aquisição das imagens com sonda 12S. As medidas ecocardiográficas seguiram as recomendações do Comitê de Padronização da Sociedade Americana de Ecocardiografia (LANG et al., 2005). Os animais foram sedados com mistura de cetamina $50 \mathrm{mg} / \mathrm{kg}$ e xilazina $23 \mathrm{mg} / \mathrm{kg}$ via intraperitoneal. A partir de imagens bidimensionais obtidas na janela paraesternal, no plano de corte longitudinal, ao nível dos músculos papilares, foram realizadas medidas lineares de espessura de parede posterior na diástole, septo interventricular na diástole, diâmetro diastólico final e diâmetro sistólico final. Tanto a fração de ejeção, medida pelo método de Simpson, como o fluxo mitral e aórtico foram obtidas a partir de imagens bidimensionais na janela paraesternal, no plano de corte apical. Os diâmetros para a aorta ascendente, arco aórtico e aorta descendente foram medidos a partir da janela supraesternal no plano longitudinal. Todas as medidas foram realizadas em três ciclos cardíacos representativos de cada animal. A medida final de cada parâmetro foi dada pela média dos resultados obtidos a cada ciclo. Todas as medidas foram realizadas de maneira cega para os grupos experimentais propostos.

\subsection{Análise da planimetria macroscópica}

A aorta foi removida, desde o arco aórtico até a aorta abdominal, aberta longitudinalmente, lavada com solução salina e imersa em solução tamponada de formalina a $10 \%$. Após a fixação, cada aorta foi corada com Scarlet $\mathrm{R}$ e fotografias foram obtidas para mensuração das lesões macroscópicas. O tamanho da aorta e as lesões foram medidas pelo programa Image $\mathrm{J}$ (National Institutes of Health, Bethesda, Maryland, EUA) e a porcentagem de lesões ateroscleróticas macroscópicas observadas foi calculada pela área de lesão/área da aorta. 


\subsection{Análise da planimetria microscópica}

Após a análise macroscópica, a região do arco aórtico foi cortada transversalmente em seguimentos de $0,5 \mathrm{~cm}$ e foi embebido em parafina $\mathrm{e}$ seccionado em cortes de $5 \mu \mathrm{m}$. A desparafinização das lâminas foi feita em 3 banhos de xilol de 10 minutos cada, seguidos de 3 banhos de etanol absoluto, 2 banhos de etanol $90 \%$ e um banho de etanol $70 \%$. As lâminas com os cortes histológicos foram então lavadas em água corrente.

A morfometria foi realizada em 5 campos de cada corte histológico do arco aórtico dos animais, corados com hematoxilina/eosina, com o auxílio de microscópio óptico com software de análise de imagens Leica Microsystems (Leica Cambridge Ltd., Cambridge, UK). Foram quantificadas a área total do arco aórtico, a área das lesões ateroscleróticas na íntima e a razão entre elas.

\subsection{Imunohistoquímica}

Para realização da imunohistoquímica, as lâminas passaram pelo procedimento de desparafinização, como descrito no item acima, a recuperação antigênica foi realizada por calor úmido e pressão em Câmara de Pressão para recuperação antigênica (Pascal, Dako, Carpinteria, EUA) com o tampão citrato 10 mM, pH 6,0 para os anticorpos anti-macrófago de coelho (clone RAM-11) e para o marcador de proliferação celular anti-Ki-67.

A atividade da peroxidase endógena foi bloqueada com 4 banhos de 5 minutos de peróxido de hidrogênio a 3\%. O bloqueio de reações inespecíficas foi feito com albumina bovina $1 \%$ em solução salina tamponada com sais de fosfato (PBS) durante 1 hora em estufa umidificada a $37^{\circ} \mathrm{C}$. Os cortes foram incubados com os anticorpos primários anti-macrófagos de coelho (Dako, Carpinteria, EUA), e anti-Ki-67 (abcam, Cambridge, UK) nas titulações 1:400 e 1:2000 respectivamente, por 18 horas a $4^{\circ} \mathrm{C}$. Como anticorpo secundário, foi utilizado o polímero SuperPicture (Thermo Scientific, Waltham, EUA), e a reação foi revelada com diaminibenzidina (DAB) e contracorada com hematoxilina de Harris.

Para análise quantitativa da expressão proteica dos antígenos RAM-11 e Ki-67, foi utilizado microscópio ótico equipado com software de análise de imagens 
Leica Microsystems. O limiar de detecção de cor foi determinado para o cromógeno DAB, baseado em uma região marcada. Imagens de 5 campos de cada corte histológico foram usadas para medir a área total da íntima e a área de marcação marrom do cromógeno DAB na íntima. $A$ área marcada pelo cromógeno DAB foi calculada como porcentagem da área da íntima de cada campo. A expressão de cada antígeno em cada animal foi calculada como média de todos os campos medidos para cada corte histológico.

\subsection{Expressão proteica por Western blot}

Fragmentos das aortas foram homogeneizados em nitrogênio líquido com pistilo e graal sendo ressuspendidos em tampão de lise na presença de inibidores de protease (aprotinina $1 \mu \mathrm{g} / \mathrm{ml}$, leupetina $1 \mu \mathrm{g} / \mathrm{ml}$ e fenil-metil-sulfonil $10 \mathrm{mM}$ ) e fosfatase (pirofosfato de sódio $100 \mathrm{mM}$, fluoreto de sódio $10 \mathrm{mM}$, ortovanato de sódio $1 \mathrm{mM}$ e beta glicerofosfato $2 \mathrm{mM}$ ).

Após a determinação da concentração de proteínas pelo método de Bradford, alíquotas de 30 a 50 $\mu \mathrm{g}$ foram diluídas em tampão de amostra contendo azul de bromofenol 0,02\%, mercaptoetanol $10 \mathrm{mM}$ e dodecil sulfato de sódio $10 \%$ e foram aplicadas juntamente com um padrão de pesos moleculares em gel de poliacrilamida para separação das proteínas por eletroforese.

Posteriormente, as proteínas foram transferidas para uma membrana de nitrocelulose em sistema úmido (Semiphor, Hoefer-Pharmacia, Suécia) sendo inicialmente incubada com a solução de bloqueio (leite $5 \%$ ).

A detecção de proteínas relacionadas à inflamação (TNF-a, IL-6, MMP-2, CD68, NFKB), adesão vascular celular (VCAM-1), e apoptose (Caspase 9, caspase 3 ), foram realizadas pela incubação com os anticorpos primários, a membrana foi lavada por solução de TBS sendo posteriormente incubados com anticorpos secundários conjugados com peroxidase e revelados por método quimioluminescente (peroxidase- $\mathrm{H}_{2} \mathrm{O}_{2}$-luminol) com o kit ECL (Amersham) expondo a membrana a um fotodocumentador (Amersham Imager 600, GE). As análises das bandas proteicas foram realizadas pelo Image Quant TL (Healthcare, GE). 


\subsection{Expressão gênica por PCR quantitativo em tempo real (qRT-PCR)}

No momento da eutanásia dos animais, a aorta e o coração foram removidos e conservados em solução de RNAlater ${ }^{\circledR}$ (Ambion by Thermo Fisher Scientific, EUA). Para cada $100 \mathrm{mg}$ de tecido foram adicionados $1 \mathrm{~mL}$ do reagente TRIzol ${ }^{\circledR}$ (Invitrogen by Thermo Fisher Scientific, EUA), homogeneizados e o RNA total foi extraído, conforme instruções do fabricante. A integridade do RNA foi analisada por eletroforese e sua concentração determinada através de leitura em espectrofotômetro a densidade óptica de 260nm, no aparelho NanoDrop 2000 Spectrophotometer (Thermo Fisher Scientific Inc, EUA). O RNA isolado foi armazenado a $-80^{\circ} \mathrm{C}$ e uma alíquota de 1 ug de RNA foi utilizada para a transcrição reversa. Para cada $16 \mu \mathrm{L}$ contendo $1 \mu \mathrm{g}$ de RNA a ser reversamente transcrito foram adicionados $4 \mu \mathrm{L}$ do mix de reação SuperScript ${ }^{\circledR}$ VILO ${ }^{\text {TM }} 5 \mathrm{x}$ (SuperScript ${ }^{\circledR}$ VILO $^{\text {TM }}$ MasterMix, Invitrogen by Thermo Fisher Scientific, EUA). Cada amostra foi levemente homogeneizada e incubada por 10 minutos a $25^{\circ} \mathrm{C}$, por 60 minutos a $42^{\circ} \mathrm{C}$ e, por fim, por 5 minutos a $85^{\circ} \mathrm{C}$. Ao término da reação, os cDNAs foram diluídos 1:5 em tampão Tris-EDTA para serem utilizados na reação de qRT-PCR.

A técnica de qRT-PCR foi utilizada para análise da expressão gênica dos fatores anti- e pró-inflamatórios (IL-10, \#Oc03396940_m1; IL-1 1 , \#Oc03823250_s1; IL-18, \#Oc03399565_m1; VCAM, \#Oc03397346_m1; MCP-1, \#Oc03823583_s1; e MMP-12, \#Oc03398610_m1). Esta técnica consiste em um sistema de emissão de luz através do sistema TaqMan de detecção, que utiliza, além dos primers, sondas fluorescentes para a detecção e quantificação do produto de PCR. Esse tipo de detecção é altamente específico, não necessitando a padronização da reação.

As reações de amplificação foram realizadas no equipamento StepOnePlus Real-Time PCR System (Applied Biosystems Thermo Fisher Scientific, EUA) que contém um software que gera um gráfico de intensidade de fluorescência em função do número de ciclos de amplificação. Um limiar (threshold) é definido automaticamente, no qual a intensidade de fluorescência é estatisticamente diferente da fluorescência de fundo (background) e a curva apresenta a fluorescência da amplificação aumentando exponencialmente. O número do ciclo cuja fluorescência da amostra intercepta o threshold é chamado Ct (cycle threshold). 
Todas as reações foram realizadas em duplicata e foram consideradas aceitáveis quando apresentaram desvio padrão menor que 0,4 ou quando apresentaram diferença de $\mathrm{Ct}<1$. Em cada reação foram pipetados um volume final de 12uL, constituídos de 6uL do reagente TaqMan Gene Expression Master Mix 2x (Applied Biosystems by Thermo Fisher Scientific, EUA); 2,4uL de água MilliQ; 0,6uL do sistema TaqMan Gene Expression Assays 20x (Applied Biosystems by Thermo Fisher Scientific, EUA) específico para cada gene alvo a ser analisado, e um para o gene normalizador utilizado, o gliceraldeído-3-fosfato desidrogenase (GAPDH, \#Oc03823402_g1); no final foram adicionados 3uL do cDNA diluído (1:5). As condições de termociclagem da reação seguiram os parâmetros de fábrica do aparelho ajustados para um pré-aquecimento a $50^{\circ} \mathrm{C}$ por 2 minutos, denaturação inicial a $95^{\circ} \mathrm{C}$ por 10 minutos, seguidos de 40 ciclos a $95^{\circ} \mathrm{C}$ por 15 segundos de denaturação e $60^{\circ} \mathrm{C}$ por 1 minuto de anelamento dos primers e extensão.

A quantificação da expressão gênica relativa foi calculada através do método Ct comparativo demonstrado pelo algoritmo $2^{-\Delta \Delta C t}$ descrito por Livak e Schmittgen (2001). $\mathrm{O}$ valor de $\Delta \mathrm{Ct}$ equivale à diferença entre o $\mathrm{Ct}$ do gene de interesse e o $\mathrm{Ct}$ do gene normalizador. $\mathrm{O} \Delta \Delta \mathrm{Ct}$ dá-se pela diferença do $\Delta \mathrm{Ct}$ da amostra grupo LDE-ODNR - a média do $\Delta$ Ct do grupo LDE. O resultado representa $\circ$ número de vezes que o gene analisado tem a sua expressão aumentada ou diminuída no tecido estudado.

\subsection{Análise estatística}

Para a análise estatística, os dados foram expressos em média \pm erro padrão (EPM). Os dados quanto ao consumo de ração, variação de peso dos animais e análises laboratoriais utilizamos o teste ANOVA com pós-teste de Tukey para a realização de comparações múltiplas. Para variáveis de distribuição não normal utilizamos o teste Kruskal-Wallis com pós-teste de Dunn. O teste $t$-student foi utilizado para a análise da planimetria, Western blot e qRT-PCR. Para as variáveis de distribuição não normal utilizamos o teste de Mann-Whitney. O nível de significância estatística foi estabelecido pelo valor de $p<0,05$. Todas as análises foram realizadas pelo programa GraphPadPrism (GraphPad Software Inc., San Diego, Califórnia, EUA) versão 5.0. 


\section{RESULTADOS}

\subsection{Massa Corporal}

A massa corporal dos animais se manteve similar nos grupos LDE e LDEDNR durante todo o protocolo, como representado na Figura 2.

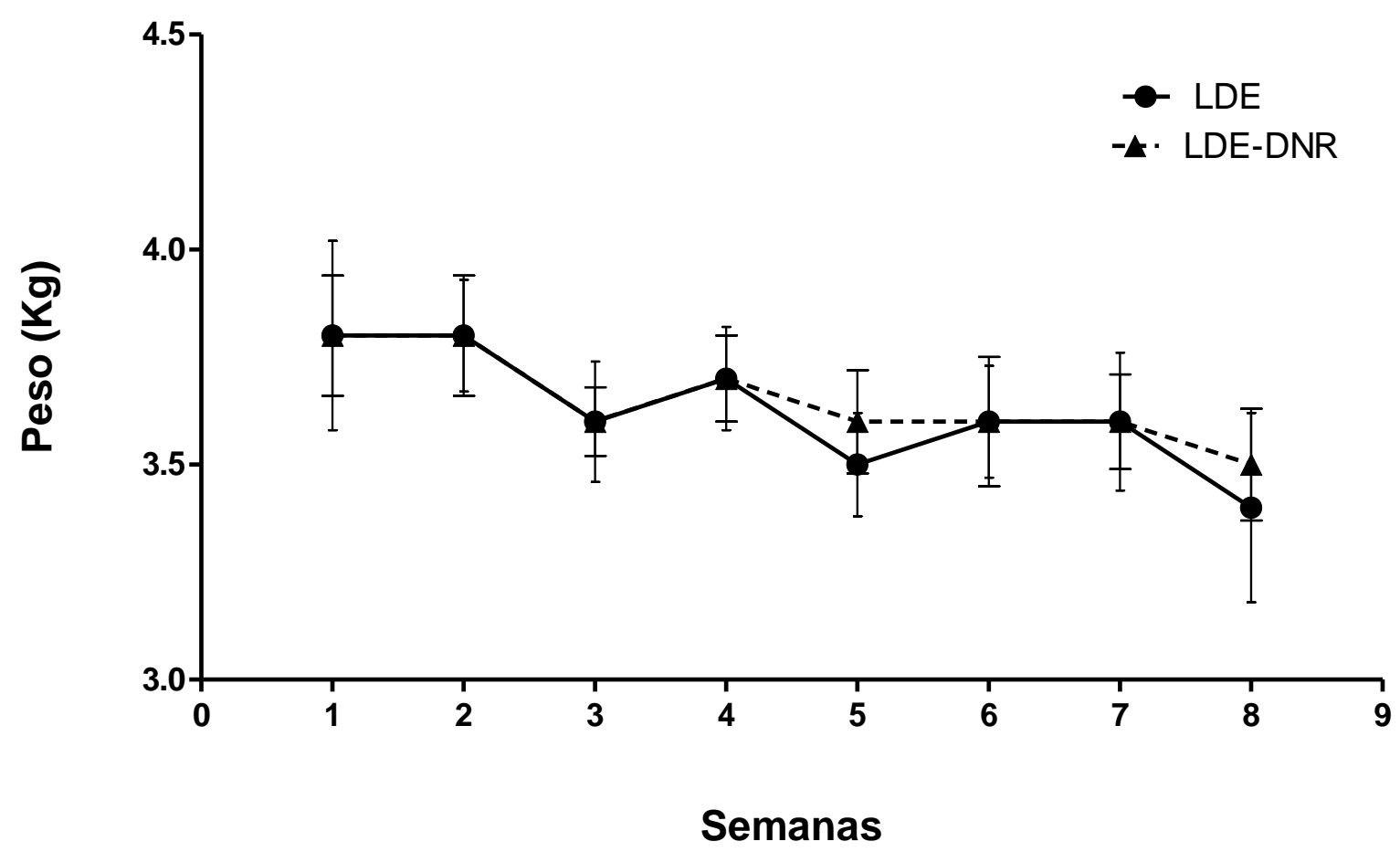

Figura 2: Massa corporal semanal em Kg dos grupos LDE e LDE-DNR. Valores expressos em Média土EPM.

\subsection{Análise do consumo de ração}

Não houve diferença no consumo semanal da ração com $1 \%$ de colesterol entre os grupos LDE e LDE-DNR durante todo protocolo. Este consumo está representado na Figura 3. 


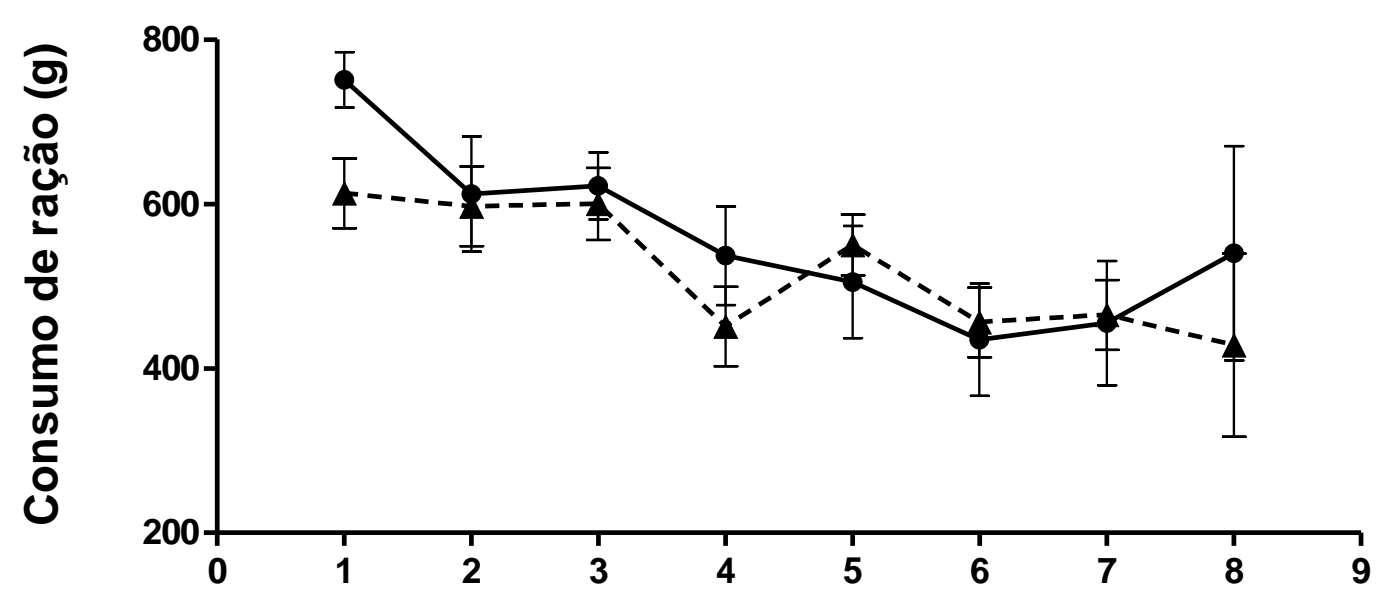

\section{Semanas}

Figura 3: Consumo semanal de ração com 1\% de colesterol dos grupos LDE e LDE-DNR. Valores expressos em Média EPM.

\subsection{Avaliação do perfil hematológico}

O perfil hematológico representado na Tabela 1 mostra que as hemácias diminuíram no pós-tratamento em comparação com o basal nos grupos LDE e LDE-DNR. A hemoglobina e o hematócrito diminuíram em ambos os grupos nos períodos pré e pós-tratamento em comparação ao período basal.

O número total de leucócitos aumentou no período pós-tratamento nos grupos LDE e LDE-DNR quando comparado com o período basal. Não houve diferença nos níveis de linfócitos, monócitos, neutrófilos e plaquetas entre os grupos LDE e LDE-DNR. 
Tabela 1: Perfil hematológico dos grupos LDE $(n=7)$ e LDE-DNR $(n=9)$ nos períodos basal, pré-tratamento e pós-tratamento.

\begin{tabular}{|c|c|c|c|c|c|c|}
\hline Hemoglobina (g/dL) & $13,1 \pm 0,4$ & $10,6 \pm 0,4^{\mathrm{a}}$ & $9,1 \pm 0,5^{a}$ & $13,6 \pm 0,5^{\mathrm{bc}}$ & $10,9 \pm 0,5^{\mathrm{ad}}$ & $10 \pm 0,5^{\text {ad }}$ \\
\hline Hematócrito (\%) & $42,6 \pm 1,3$ & $32,7 \pm 1,1^{\mathrm{a}}$ & $29 \pm 1,9^{a}$ & $43,2 \pm 1,5^{\mathrm{bc}}$ & $34,1 \pm 1,6^{\text {ad }}$ & $32,8 \pm 1,6^{\mathrm{ad}}$ \\
\hline Leucócitos $\left(10^{3} / \mathrm{mm}^{3}\right)$ & $11,4 \pm 0,7$ & $14,0 \pm 0,9$ & $20,8 \pm 3,0^{\mathrm{a}}$ & $10,4 \pm 0,6$ & $13,0 \pm 0,8$ & $17,4 \pm 1,5^{d}$ \\
\hline Neutrófilos (\%) & $37,6 \pm 4,2$ & $39,3 \pm 2,1$ & $40,6 \pm 4,8$ & $34,1 \pm 4,3$ & $34,8 \pm 2,9$ & $29,8 \pm 2,1$ \\
\hline Plaquetas $\left(10^{3} / \mathrm{mm}^{3}\right)$ & $378,4 \pm 34,6$ & $349,3 \pm 20,9$ & $292,0 \pm 21,9$ & $287 \pm 18,6$ & $295 \pm 31,8$ & $276 \pm 30$ \\
\hline
\end{tabular}


DNR, daunorrubicina. Valores expressos em média \pm EPM. ${ }^{a} p<0.001$ vs LDE basal, ${ }^{b} p<0.001$ vs LDE pré-tratamento, ${ }^{c} p<0.001$ vs LDE pós-tratamento, ${ }^{d} p<0.001$ vs LDE-DNR basal.

\subsection{Análise do perfil bioquímico}

Após a dieta rica em colesterol, foi observado um aumento de 40 vezes do colesterol total, do HDL-C em 20 vezes, do não-HDL em 60 vezes e dos triglicérides em 3 vezes no período de pós-tratamento comparado com o período basal dos grupos LDE e LDE-DNR (Tabela 2).

Houve um aumento da ureia somente no grupo LDE quando comparado o período basal e pós-tratamento. Não houve diferença na concentração de creatinina sérica em nenhum dos períodos analisados.

Nas análises de enzimas hepáticas, a concentração de AST aumentou no grupo LDE-DNR antes do início do tratamento, no período de pré-tratamento e esse aumento da concentração de AST também foi encontrado no período póstratamento quando comparado com o período basal desse mesmo grupo. Não houve diferença nos níveis de ALT nos grupos LDE e LDE-DNR. 
Tabela 2: Perfil bioquímico dos grupos LDE $(n=7)$ e LDE-DNR $(n=9)$ nos períodos basal, pré-tratamento e pós-tratamento.

\begin{tabular}{|c|c|c|c|c|c|c|}
\hline & \multirow[b]{2}{*}{ Basal } & \multicolumn{3}{|c|}{ LDE } & \multicolumn{2}{|c|}{ LDE-DNR } \\
\hline & & $\begin{array}{c}\text { Pré- } \\
\text { tratamento }\end{array}$ & $\begin{array}{c}\text { Pós- } \\
\text { tratamento }\end{array}$ & Basal & $\begin{array}{l}\text { Pré- } \\
\text { tratamento }\end{array}$ & $\begin{array}{l}\text { Pós- } \\
\text { tratamento }\end{array}$ \\
\hline \multicolumn{7}{|l|}{ Colesterol (mg/dL) } \\
\hline Total & $56 \pm 14,5$ & $1039 \pm 77,8$ & $1972 \pm 193,3^{a}$ & $37 \pm 2,5^{c}$ & $909 \pm 134,3$ & $1781 \pm 200^{\mathrm{ad}}$ \\
\hline HDL - C & $24 \pm 4,9$ & $150 \pm 27,6$ & $374 \pm 71^{a b}$ & $18 \pm 2,9^{c}$ & $151 \pm 14,3^{c}$ & $406 \pm 83,5^{\text {abde }}$ \\
\hline Não-HDL & $32 \pm 10,4$ & $889 \pm 54,4$ & $1598 \pm 156,6^{a}$ & $19 \pm 2,6^{c}$ & $757 \pm 124,6$ & $1375 \pm 131^{\text {ad }}$ \\
\hline Triglicérides(mg/dL) & $63 \pm 7,6$ & $111 \pm 33,5$ & $256 \pm 54,8^{a}$ & $66,8 \pm 13,2^{c}$ & $82,9 \pm 17,9^{c}$ & $160 \pm 28,1$ \\
\hline
\end{tabular}




\begin{tabular}{|c|c|c|c|c|c|c|}
\hline Uréia (mg/dL) & $30,6 \pm 2,1$ & $50 \pm 7,5$ & $67 \pm 9,9^{f}$ & $125 \pm 7,9$ & $100 \pm 4,1$ & $148,5 \pm 23^{f}$ \\
\hline Creatinina (mg/dL) & $1,0 \pm 0,07$ & $1,2 \pm 0,1$ & $1,3 \pm 0,1$ & $1,3 \pm 0,06$ & $1,2 \pm 0,07$ & $1,4 \pm 0,1$ \\
\hline AST (U/L) & $39,1 \pm 7,8$ & $64,2 \pm 13,7$ & $80,6 \pm 22,3$ & $36,9 \pm 3,5$ & $92,1 \pm 19,9^{h}$ & $141,4 \pm 32,8^{\text {fh }}$ \\
\hline ALT (U/L) & $35,1 \pm 7,3$ & $37,3 \pm 11,7$ & $65,4 \pm 7,5$ & $49,1 \pm 7,7$ & $71,1 \pm 12,8$ & $99,7 \pm 20^{f g}$ \\
\hline
\end{tabular}

DNR, daunorrubicina; HDL, high density lipoprotein; LDL, low density lipoprotein; AST, aspartato aminotransferase; ALT, alanina aminotransferase. Valores expressos em média \pm EPM. ${ }^{a} p<0.001$ vs LDE basal, ${ }^{b} p<0.001$ vs LDE pré-tratamento, ${ }^{c} p<0.001$ vs LDE pós-tratamento, ${ }^{d} p<0.001$ vs LDE-DNR basal, ${ }^{e} p<0.001$ vs LDE-DNR pré-tratamento, ${ }^{f} p<0.01$ vs LDE basal, ${ }^{g} p<0.01$ vs LDE pré-tratamento, ${ }^{h} p<0.01$ vs LDE-DNR basal. 


\subsection{Planimetria macroscópica}

$\mathrm{Na}$ análise macroscópica das aortas dos coelhos ateroscleróticos, a área de lesão e porcentagem de lesão do grupo LDE-DNR foi $50 \%$ menor que no grupo LDE, como representado na Figura 4 e Tabela 3.

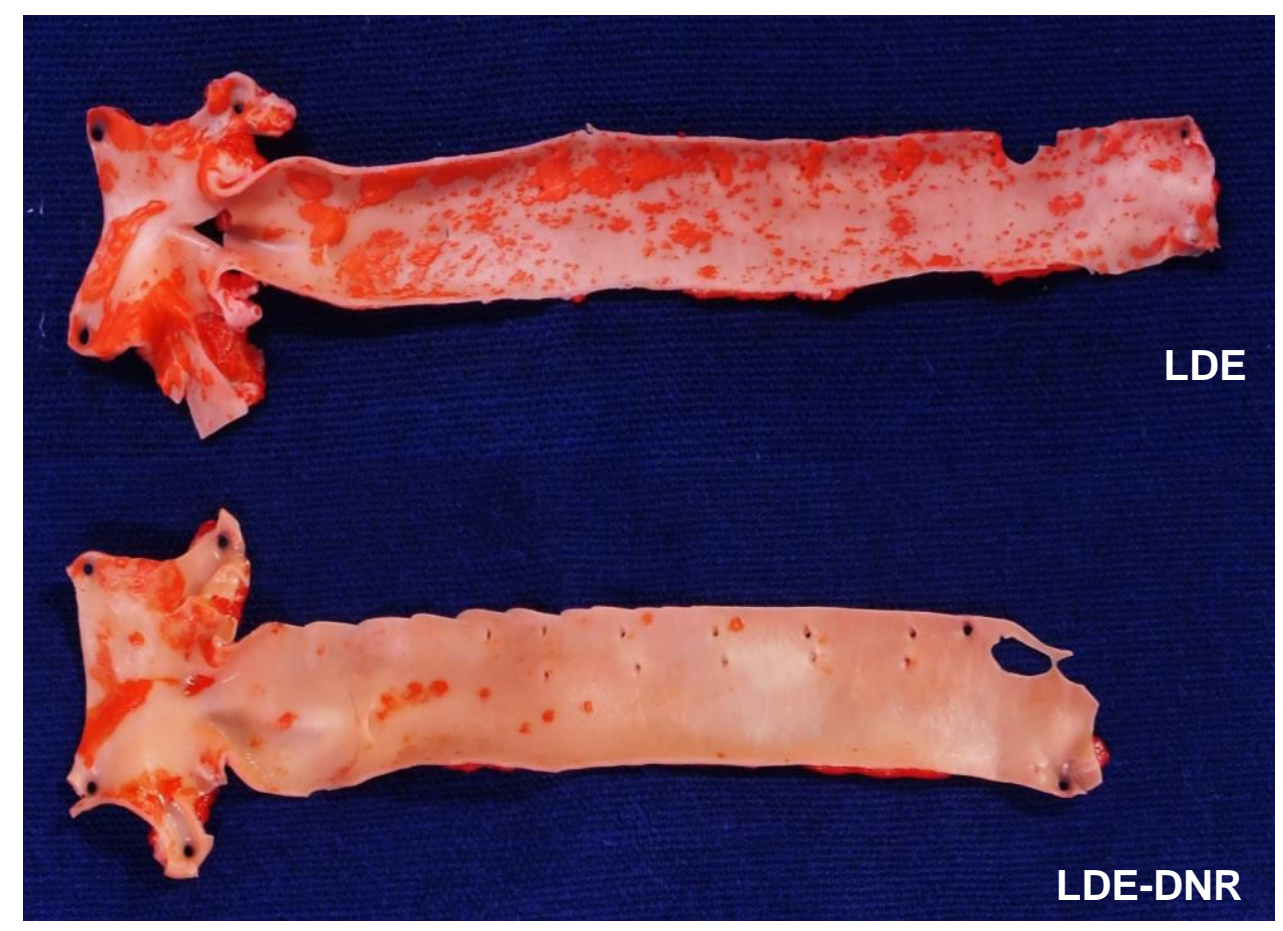

Figura 4: Fotos representativas das aortas dos coelhos dos grupos LDE e LDE-DNR. 
Tabela 3: Análise macroscópica da área das aortas, área de lesão, e porcentagem da lesão dos grupos LDE $(n=7)$ e LDE-DNR $(n=9)$.

\begin{tabular}{|c|c|c|}
\hline Macroscopia & LDE & LDE-DNR \\
\hline Área da aorta $\left(\mathrm{px}^{2} \times 10^{3}\right)$ & $1355 \pm 51$ & $1284 \pm 38$ \\
\hline Área de lesão $\left(p x^{2} \times 10^{3}\right)$ & $293 \pm 66$ & $150 \pm 25^{*}$ \\
\hline Porcentagem de lesão (\%) & $21,2 \pm 4,3$ & $11,5 \pm 1,7^{*}$ \\
\hline
\end{tabular}

\subsection{Planimetria Microscópica}

$\mathrm{Na}$ análise microscópica dos cortes histológicos do arco aórtico dos grupos LDE e LDE-DNR, o grupo LDE-DNR apresentou a área da íntima 55\% menor que no grupo LDE. A Figura 5 representa esses cortes histológicos dos arcos aórticos dos coelhos do grupo LDE e LDE-DNR.

A

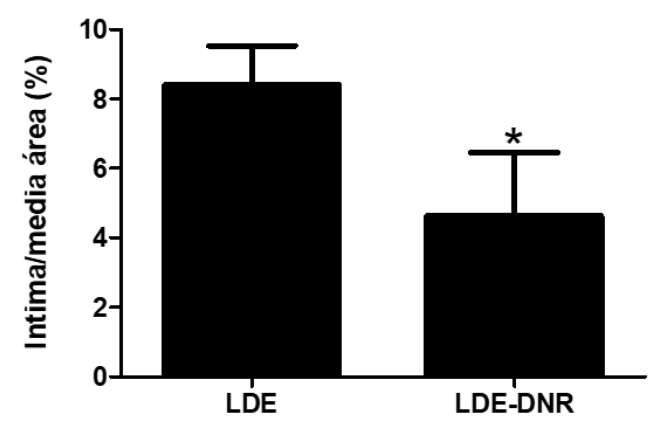

B

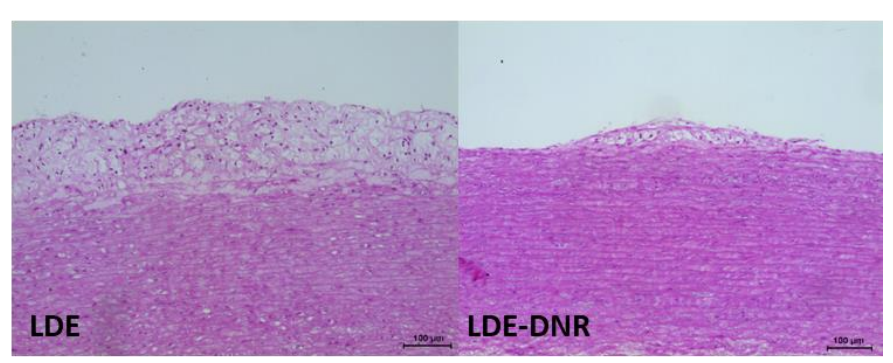

Figura 5: (A) Razão da área da íntima e média do arco aórtico dos coelhos dos grupos LDE $(n=7)$ e LDE-DNR ( $n=9)$. (B) Imagem representativa de corte histológico do arco aórtico dos coelhos dos grupos LDE e LDE-DNR. Coloração de hematoxilina e eosina. Aumento de 100x. Valores expressos em Média $\pm E P M$. ${ }^{*} p<0,05$. 


\subsection{Análise Ecocardiográfica}

Os dados ecocardiográficos de coelhos no período pós-tratamento estão representados Tabela 4. Não houve diferença nos diâmetros finais do ventrículo esquerdo diastólico (DD) e sistólico (DS) e nos diâmetros finais dos volumes do ventrículo esquerdo diastólico (VDF) e sistólico (VSF) nos grupos LDE e LDEDNR. A espessura da parede do septo interventricular (SIV), a espessura da parede posterior (PP) e a massa do ventrículo esquerdo (mVE) não foram alteradas. Não houve diferença na função sistólica representada pela fração de ejeção (FE) e fração de encurtamento (Fen) e na função diastólica representada pelo tempo de relaxamento isovolumétrico da onda $E$ / A (TRIV) e pelo tempo de desaceleração da onda E (TD) nos grupos LDE e LDE-DNR. Além disso, as análises dos diâmetros da aorta ascendente e descendente e do arco aórtico foram semelhantes nos grupos LDE e LDE-DNR.

Tabela 4: Análise ecocardiográfica de grupos de coelhos saudáveis (Controle) $(n=3)$, LDE $(n=7)$ e LDE-DNR $(n=9)$.

\begin{tabular}{lccc}
\hline & Controle & LDE & LDE-DNR \\
& $(\mathbf{n}=\mathbf{3})$ & $(\mathbf{n}=7)$ & $(\mathbf{n}=9)$ \\
\hline $\mathrm{DD}(\mathrm{mm} / \mathrm{kg})$ & $4,3 \pm 0,3$ & $4,7 \pm 0,1$ & $4,6 \pm 0,1$ \\
$\mathrm{DS}(\mathrm{mm} / \mathrm{kg})$ & $3,3 \pm 0,5$ & $3,4 \pm 0,2$ & $3,2 \pm 0,1$ \\
$\operatorname{VDF}(\mathrm{ml} / \mathrm{kg})$ & $0,7 \pm 0,1$ & $1,7 \pm 0,2$ & $1,5 \pm 0,2$ \\
$\operatorname{VSF}(\mathrm{ml} / \mathrm{kg})$ & $0,20 \pm 0,01$ & $0,60 \pm 0,10$ & $0,50 \pm 0,08$ \\
$\operatorname{SIV}(\mathrm{mm} / \mathrm{kg})$ & $0,70 \pm 0,05$ & $0,70 \pm 0,50$ & $0,70 \pm 0,60$ \\
$\mathrm{PP}(\mathrm{mm} / \mathrm{kg})$ & $0,71 \pm 0,02$ & $0,71 \pm 0,05$ & $0,65 \pm 0,03$ \\
$\mathrm{mVE}(\mathrm{mg} / \mathrm{kg})$ & $14 \pm 1$ & $12 \pm 1$ & $11 \pm 1$ \\
FE $(\%)$ & $58 \pm 2$ & $63 \pm 2$ & $66 \pm 2$ \\
\hline
\end{tabular}




\begin{tabular}{|c|c|c|c|}
\hline Fen (\%) & $25 \pm 8$ & $29 \pm 4$ & $31 \pm 2$ \\
\hline Onda $E / A$ & $1,3 \pm 0,2$ & $1,7 \pm 0,2$ & $1,6 \pm 0,1$ \\
\hline TRIV (ms) & $0,30 \pm 0,02$ & $0,50 \pm 0,07$ & $0,40 \pm 0,05$ \\
\hline TD (ms) & $0,4 \pm 0,1$ & $0,7 \pm 0,1$ & $0,9 \pm 0,2$ \\
\hline Aorta Asc. (mm) & $2,5 \pm 0,2$ & $2,8 \pm 0,1$ & $2,6 \pm 0,1$ \\
\hline Aorta Desc. (mm) & $7,4 \pm 0,4$ & $8,0 \pm 0,2$ & $7,7 \pm 0,2$ \\
\hline Arco Aórtico (mm) & $1,8 \pm 0,1$ & $2,2 \pm 0,1$ & $1,9 \pm 0,1$ \\
\hline \multicolumn{4}{|c|}{$\begin{array}{l}\text { DNR, daunorrubicina; DD, diâmetro diastólico do ventrículo esquerdo; DS, diâmetro sistólico do } \\
\text { ventrículo esquerdo; VDF, volume diastólico final; VSF, volume sistólico final; SIV, espessura do } \\
\text { septo intraventricular; PP, espessura da parede posterior; mVE, massa do ventrículo esquerdo; } \\
\text { FE, fração de ejeção; Fen, fração de encurtamento; TRIV, tempo de relaxamento } \\
\text { isovolumétrico; TD, tempo de desaceleração da onda E; Asc., ascendente; Desc., descendente. } \\
\text { Dados expressos em média } \pm \text { EPM. }\end{array}$} \\
\hline
\end{tabular}

\subsection{Análise Imunohistoquímica}

$\mathrm{Na}$ Figura 6 estão representadas as análises de proliferação celular marcadas pela expressão de Ki-67. Não houve diferença na expressão de Ki-67 nos grupos LDE e LDE-DNR.

A

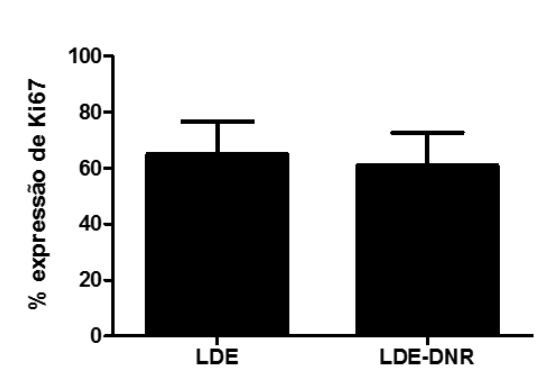

B

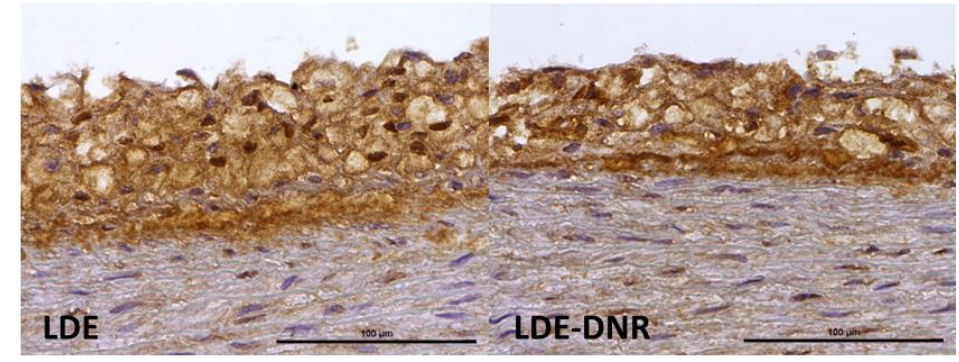

Figura 6: (A) Porcentagem do marcador Ki-67 em núcleo com proliferação celular nos grupos LDE $(n=7)$ e LDE-DNR ( $n=9)$ (B) Imagens representativas de núcleos marcados positivamente com Ki-67 (núcleos marrons), e negativamente (núcleos azuis). 


\subsection{Análise da expressão proteica por Western blot e expressão gênica por qRT-PCR}

\subsubsection{Processo Inflamatório}

As análises de Western blot nas aortas dos coelhos foram realizadas para mediadores inflamatórios nos grupos LDE e LDE-DNR como representado na Figura 7A. A expressão da proteína marcadora de macrófago (CD68) foi 43\% menor no grupo LDE-DNR quando comparado ao grupo LDE (Figura 7B). A Figura 7C possui imagens representativas da aorta ascendente dos grupos LDE e LDEDNR com macrófagos marcados pela imunohistoquímica identificados em marrom. Além disso, como apresentado na Figura 8A, a expressão gênica de MCP-1 na aorta foi menor no grupo LDE-DNR quando comparado ao LDE. A expressão proteica da citocina IL-6 e TNF- $\alpha$ foi aproximadamente $40 \%$ menor no grupo de tratamento com LDE-DNR quando comparado ao grupo LDE (Figura 7D-E). Entretanto, não houveram diferenças nas expressões gênicas das citocinas MCP1, IL-18, IL-10 e IL-1 $\beta$ entre os grupos LDE-DNR e LDE, tanto nas aortas quanto no tecido cardíaco desses animais (Figura 8B-D e Figura 9 A-D). 

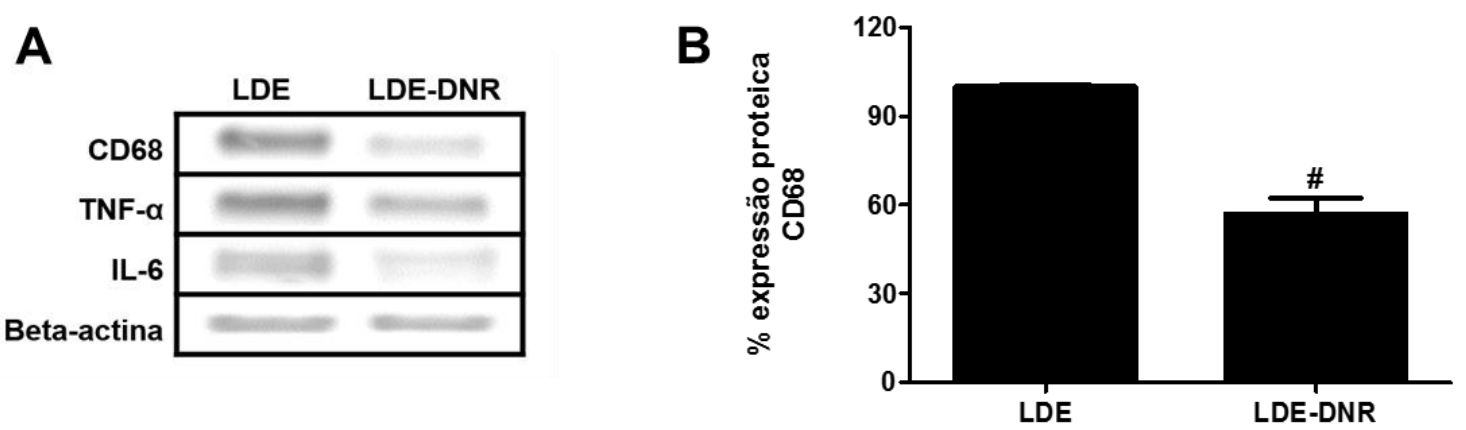

C
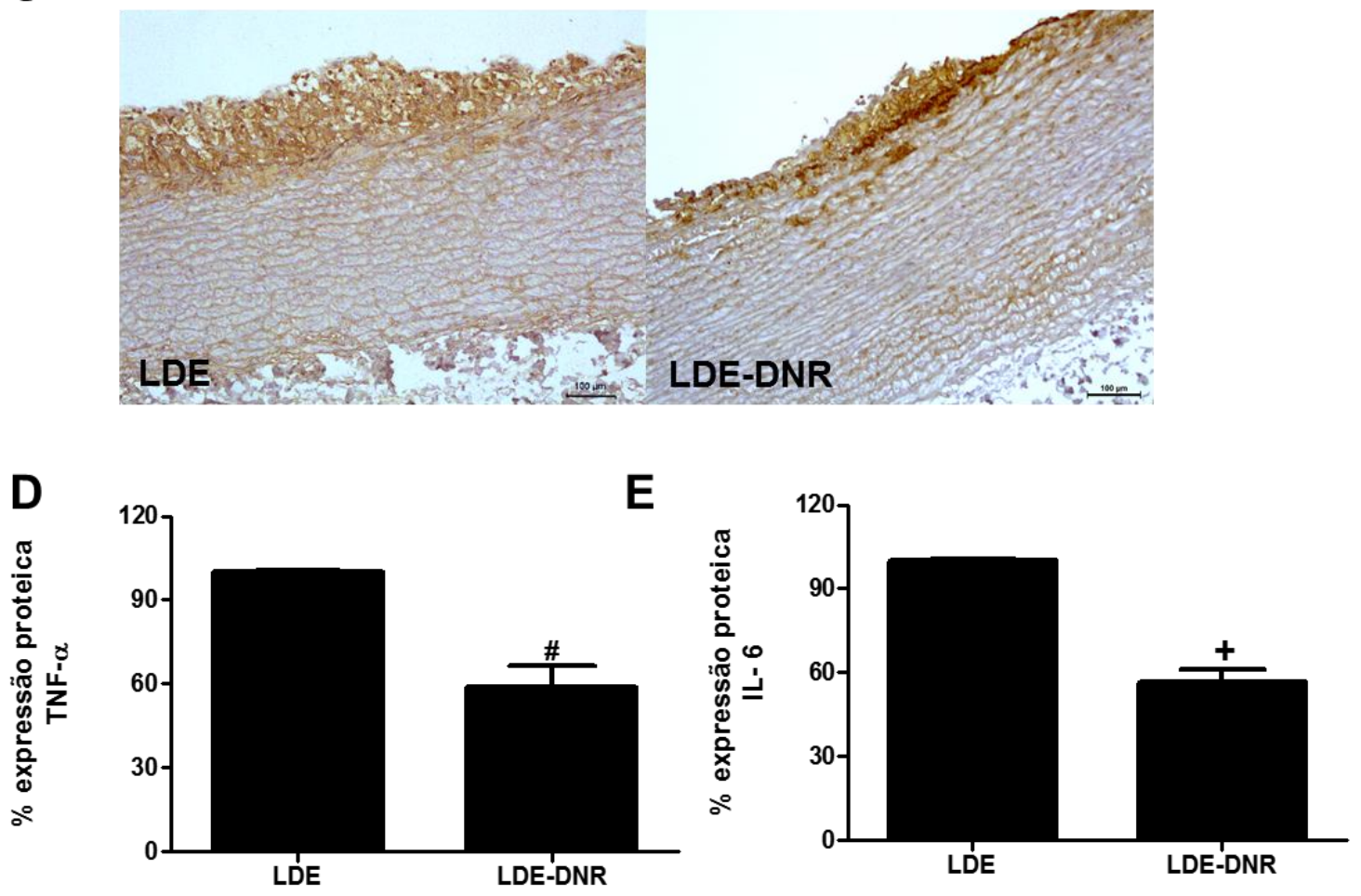

Figura 7: (A) Imagem representativa de bandas de Western blot para as proteínas CD68, TNF-a e IL-6. (B) Expressão proteica de CD68 na aorta ascendente dos coelhos dos grupos LDE $(n=3)$ e LDE-DNR $(n=4)$. (C) Imagens representativas de imunohistoquímica para macrófagos no arco aórtico marcado com cromógeno DAB nos grupos LDE e LDE-DNR. (D) Expressão proteica de TNF- $\alpha$ na aorta ascendente dos coelhos dos grupos LDE $(n=3)$ e LDE-DNR $(n=4)$. (E) Expressão proteica de IL-6 na aorta ascendente dos coelhos dos grupos LDE $(n=3)$ e LDE-DNR $(n=4)$. Valores expressos em Média $\pm E P M .{ }^{+} p<0,001 ;{ }^{*} p<0,01$. 
A

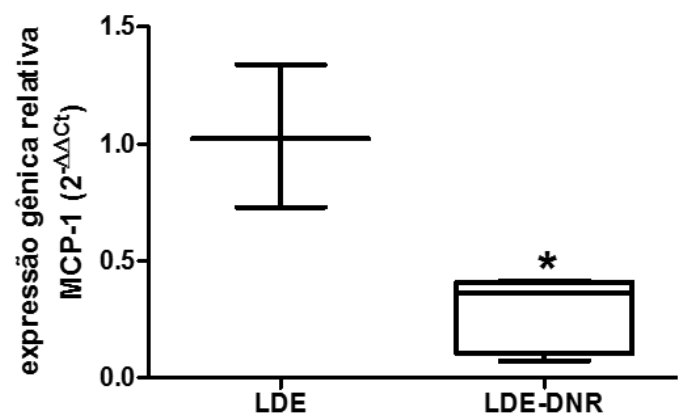

C

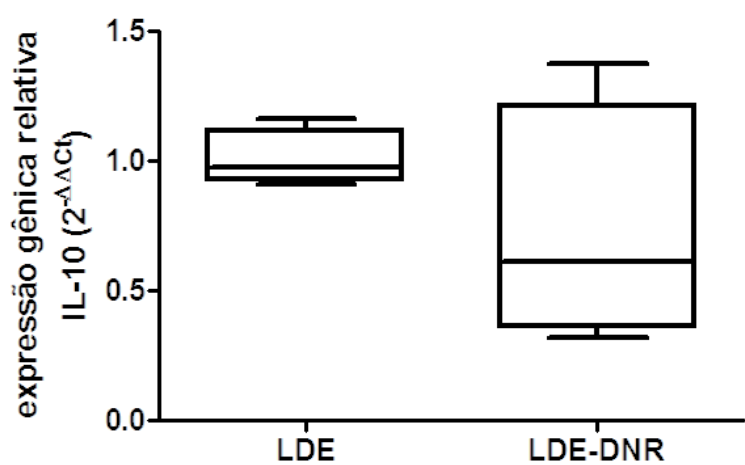

B

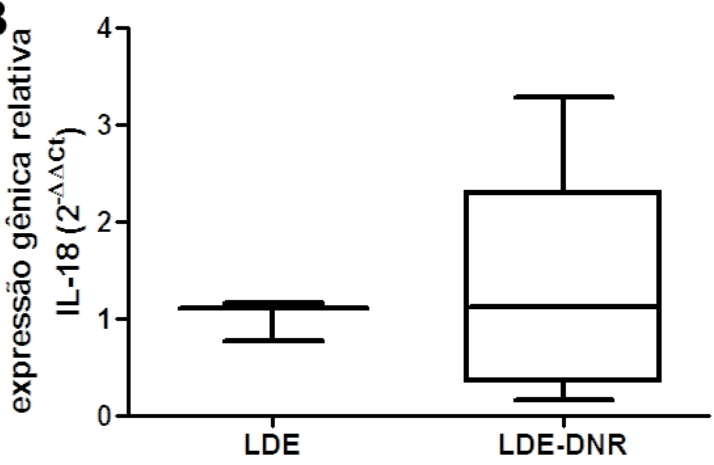

D

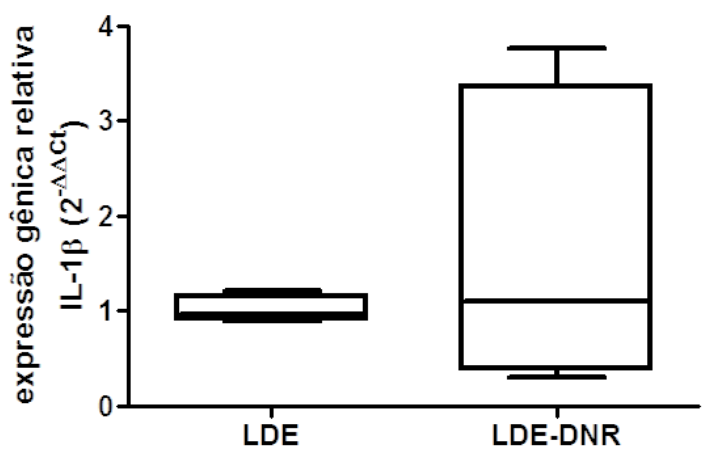

Figura 8: (A) Expressão gênica de MCP-1 na aorta ascendente dos coelhos dos grupos LDE $(n=6)$ e LDE-DNR $(n=6)$. (B) Expressão gênica de IL-18 na aorta ascendente dos coelhos dos grupos $\operatorname{LDE}(n=6)$ e LDE-DNR $(n=6)$. (C) Expressão gênica de IL-10 na aorta ascendente dos coelhos dos grupos LDE $(n=6)$ e LDE-DNR ( $n=6)$. (D) Expressão gênica de IL-1 $\beta$ na aorta ascendente dos coelhos dos grupos LDE $(n=6)$ e LDE-DNR $(n=6)$. Valores expressos em Média \pm EPM. ${ }^{*} p<0,05$. 
A

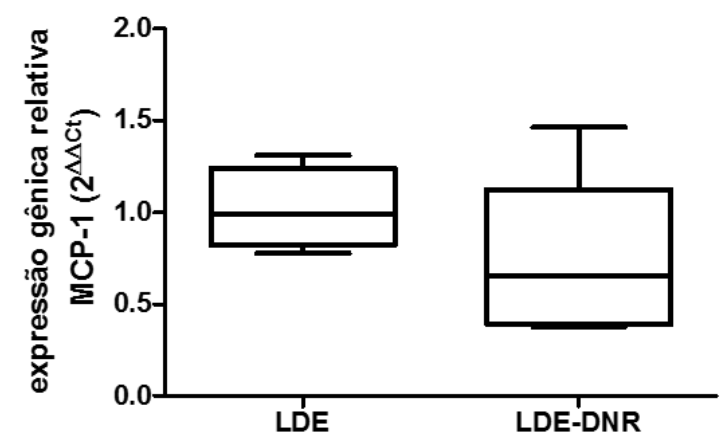

C

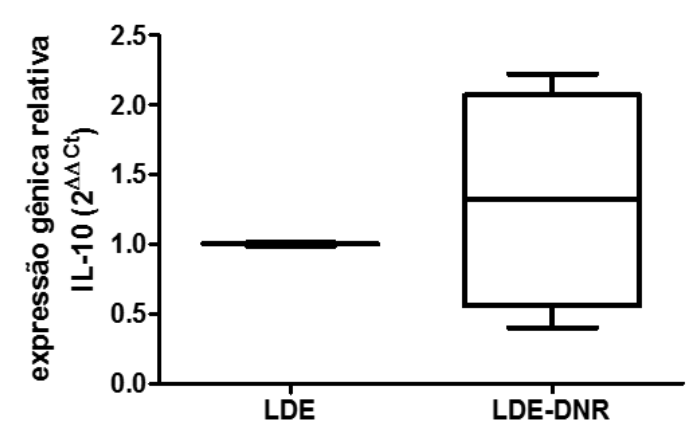

B

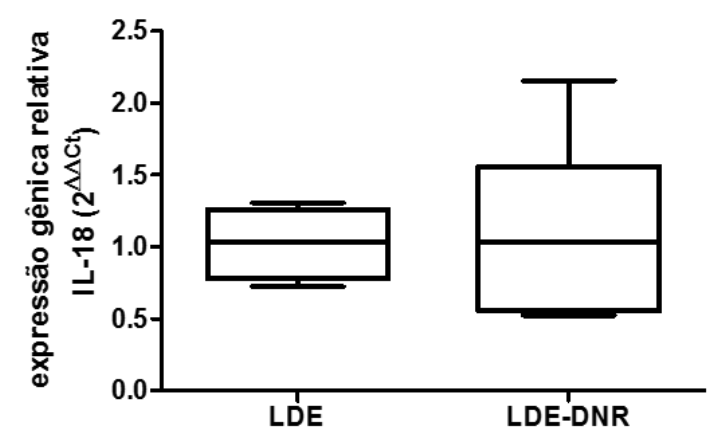

D

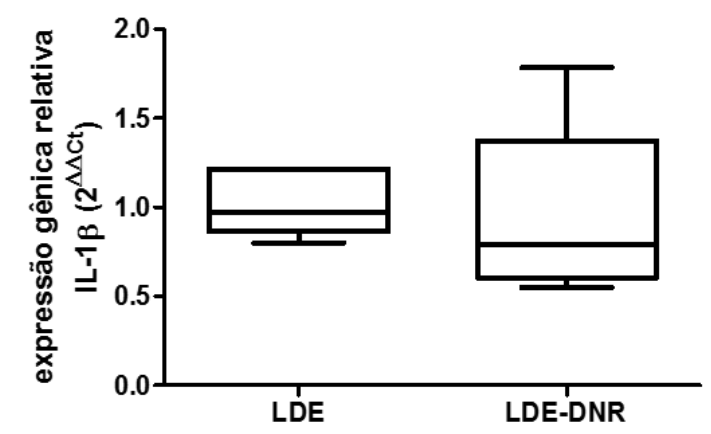

Figura 9: (A) Expressão gênica de MCP-1 no tecido cardíaco dos coelhos dos grupos LDE $(n=6)$ e LDE-DNR ( $n=6)$. (B) Expressão gênica de IL-18 no tecido cardíaco dos coelhos dos grupos LDE $(n=6)$ e LDE-DNR $(n=6)$. (C) Expressão gênica de IL-10 no tecido cardíaco dos coelhos dos grupos LDE $(n=6)$ e LDE-DNR $(n=6)$. (D) Expressão gênica de IL-1 $\beta$ no tecido cardíaco dos coelhos dos grupos LDE $(n=6)$ e LDE-DNR $(n=6)$.

\subsubsection{Adesão Vascular Celular}

A Figura 10A mostra as bandas representativas de VCAM-1. A expressão proteica de VCAM-1 foi $45 \%$ menor no grupo LDE-DNR quando comparado com o grupo LDE (Figura 10B). Além disso, a expressão gênica relativa de VCAM-1 da aorta ascendente foi menor no grupo LDE-DNR quando comparado com o grupo LDE, como representado na figura 10C. Para as análises da expressão gênica relativa desse mesmo gene no tecido cardíaco, não houve diferença entre os grupos LDE e LDE-DNR (Figura 11). 
A

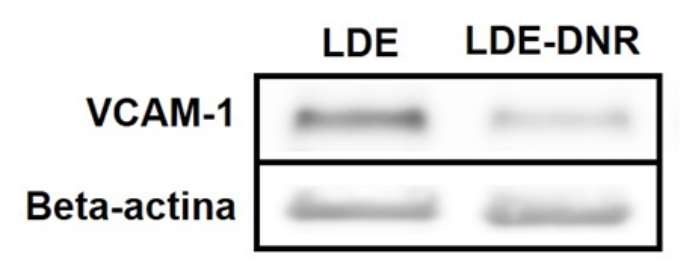

C

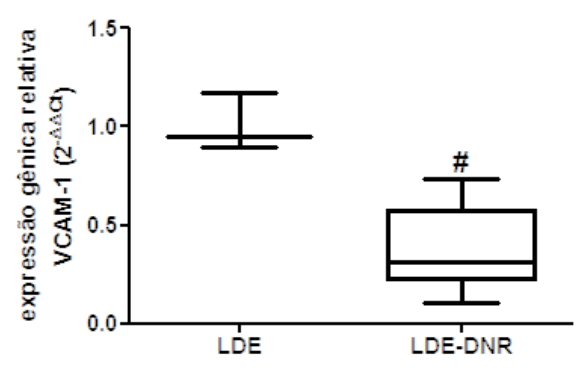

B

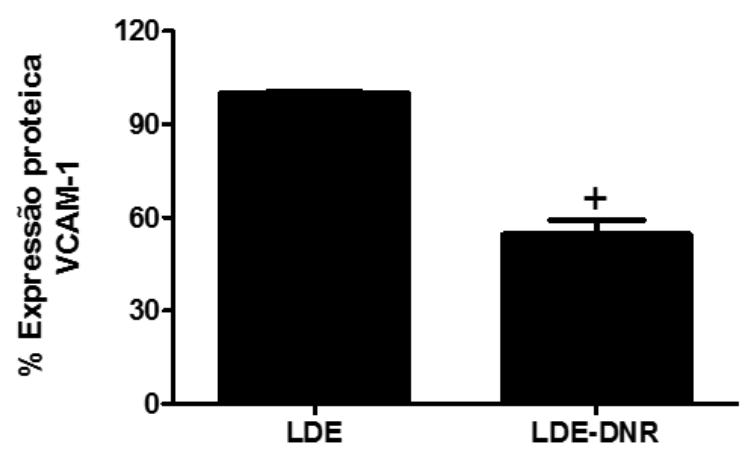

Figura 10: (A) Imagem representativa de bandas de Western blot para a proteína VCAM-1. (B) Expressão proteica de VCAM-1 na aorta ascendente dos coelhos dos grupos LDE $(n=3)$ e LDE-DNR $(n=4)$. (C) Expressão gênica de VCAM1 na aorta ascendente dos coelhos dos grupos LDE $(n=6)$ e LDE-DNR $(n=6)$. Valores expressos em Média \pm EPM. ${ }^{+} p<0,001 ;{ }^{\#} p<0,01$.

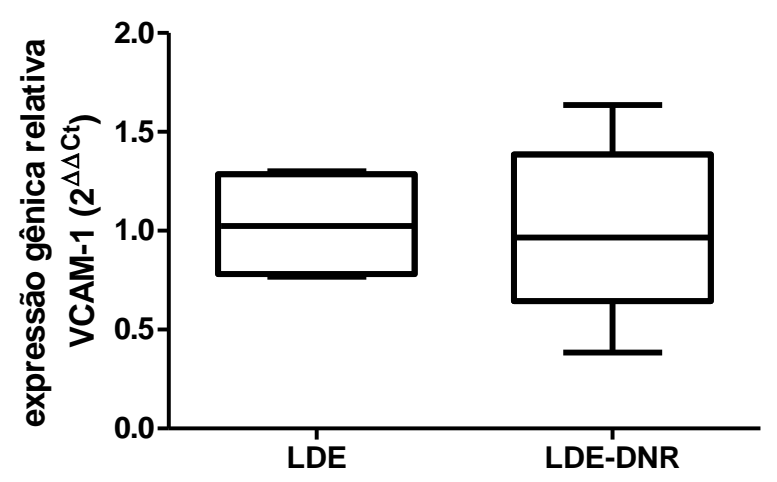

Figura 11: Expressão gênica de VCAM-1 no tecido cardíaco dos coelhos dos grupos LDE $(n=6)$ e LDE-DNR $(n=6)$. 


\subsubsection{MMPs}

A Figura 12A mostra bandas representativas de Western blot de MMP-2 e MMP-9. A expressão proteica de MMP-2 foi aproximadamente 50\% menor (Figura 12B). Não houve diferença na expressão proteica da MMP-9 entre os grupos LDE e LDE-DNR (Figura 12C). Porém, a expressão gênica de MMP-12 foi acentuadamente menor no grupo LDE-DNR quando comparado ao grupo LDE (Figura 12D).

A
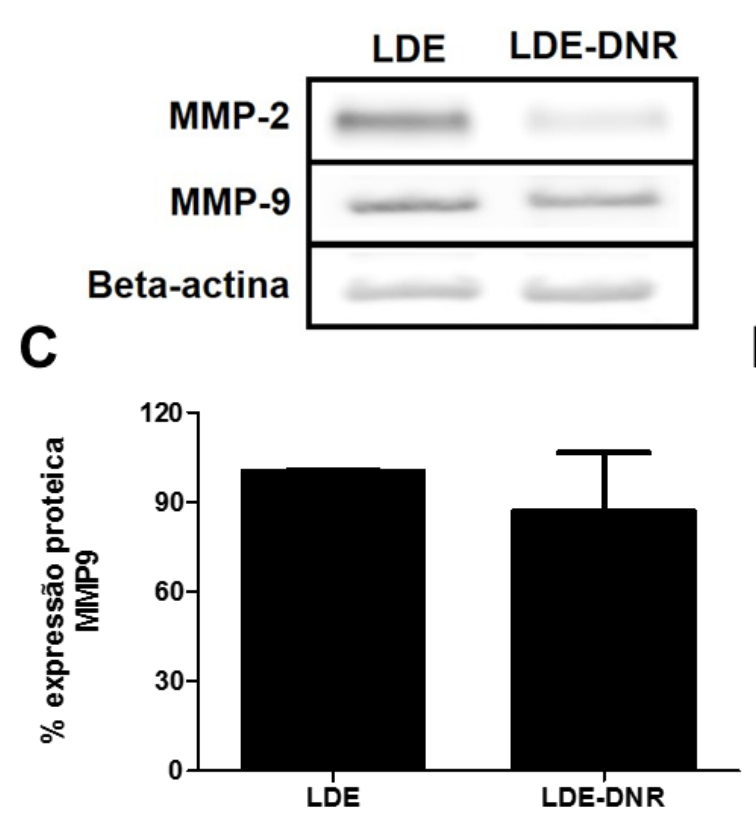

B

D
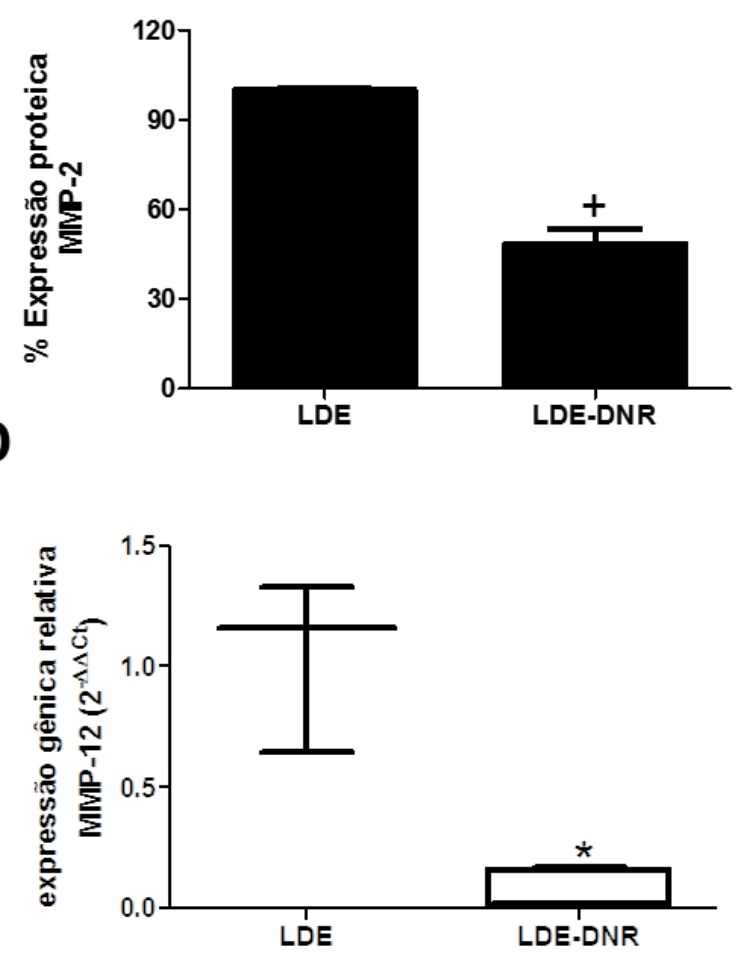

Figura 12: (A) Imagem representativa de bandas de Western blot para as proteínas MMP-2 e MMP-9. (B) Expressão proteica de MMP-2 na aorta ascendente dos coelhos dos grupos LDE $(n=3)$ e LDE-DNR $(n=4)$. (C) Expressão proteica de MMP-9 na aorta ascendente dos coelhos dos grupos LDE $(n=3)$ e LDE-DNR ( $n=4)$. (D) Expressão gênica de MMP-12 na aorta ascendente dos coelhos dos grupos LDE $(n=6)$ e LDE-DNR $(n=6)$. Valores expressos em Média \pm EPM. ${ }^{+} p<0,001 ;{ }^{*} p<0,05$. 


\subsubsection{Morte Celular}

A Figura 13A representa as bandas de Western blot dos marcadores de apoptose celular nos grupos LDE e LDE-DNR. A expressão proteica dos marcadores pró-apoptóticos, Caspases 3, 9 e Bax, foi cerca de $50 \%$ menor no grupo LDE-DNR em comparação ao grupo LDE (Figura 13B-D).

A
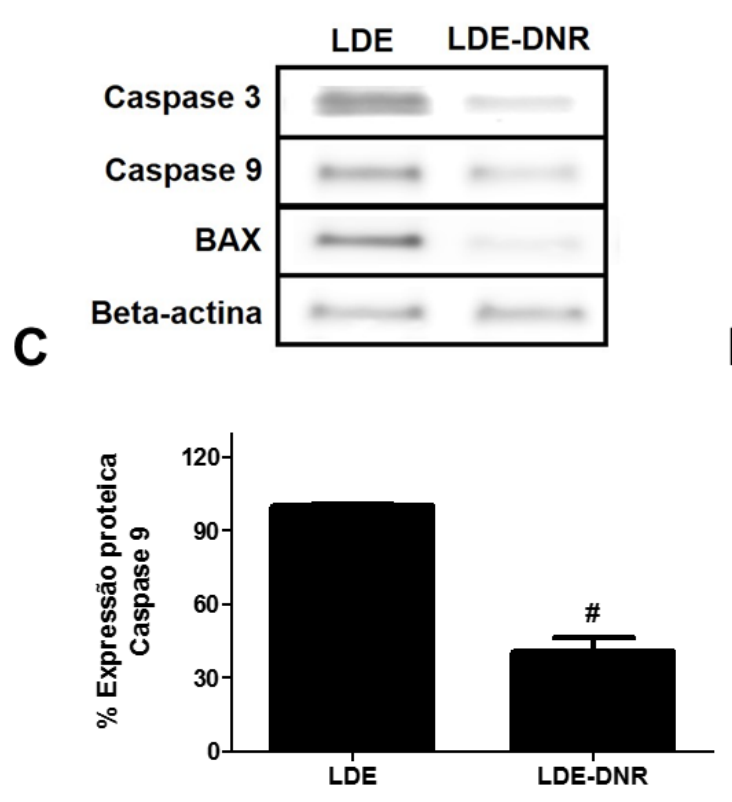

B

D
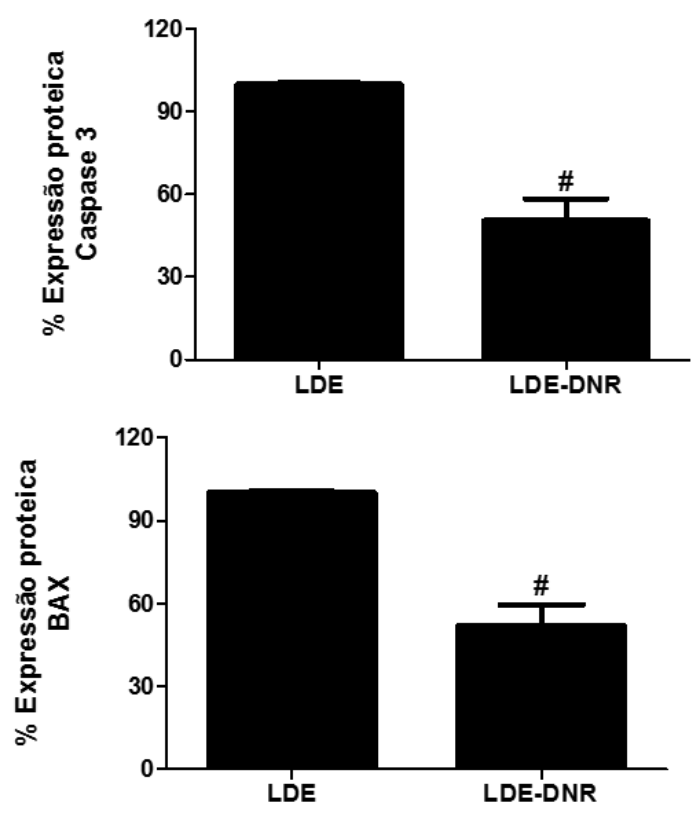

Figura 13: (A) Imagem representativa de bandas de Western blot para as proteínas Caspases 3 e 9 e BAX. (B) Expressão proteica de caspase 3 em aorta ascendente dos coelhos dos grupos LDE $(n=3)$ e LDE-DNR $(n=4)$. (C) Expressão proteica de Caspase 9 na aorta ascendente dos coelhos dos grupos LDE $(n=3)$ e LDE-DNR ( $n=4)$. (D) Expressão proteica de Bax na aorta ascendente dos coelhos dos grupos LDE $(n=3)$ e LDE-DNR $(n=4)$. Valores expressos em Média $\pm E P M$. ${ }^{\#} \mathrm{p}<0,01$. 


\subsubsection{VEGF}

As bandas representativas de Western blot do VEGF são mostradas na Figura 14A. A expressão da proteína VEGF na aorta ascendente foi $50 \%$ menor no grupo LDE-DNR quando comparado ao grupo LDE (Figura 14B).

A

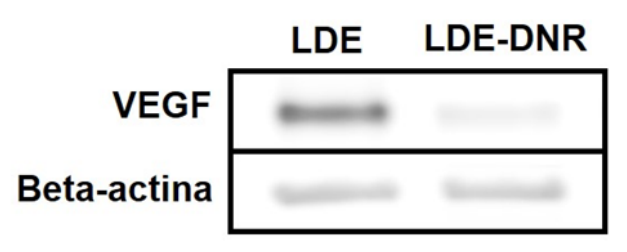

B

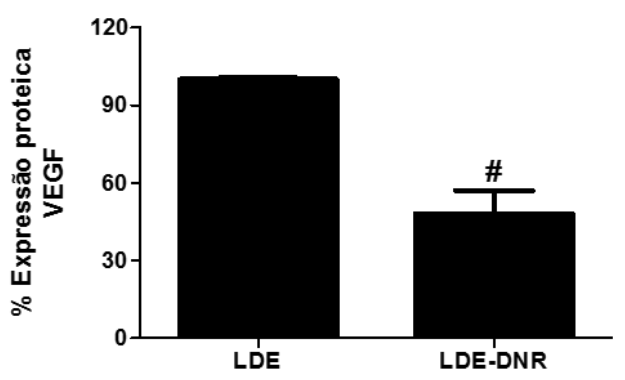

Figura 14: (A) Imagem representativa de bandas de Western blot para a proteína VEGF. (B) Expressão proteica de VEGF em arco aórtico dos coelhos dos grupos LDE $(n=3)$ e LDE-DNR $(n=4)$. Valores expressos em Média $\pm E P M . ~ \# p<0,01$. 


\section{DISCUSSÃO}

A LDE criada por Maranhão et al., (1992) vem demonstrando grande sucesso em carrear quimioterápicos no tratamento de aterosclerose em estudos clínicos e experimentais, diminuindo as lesões aórticas e reduzindo os efeitos colaterais desses fármacos (TAVARES et al., 2011; BULGARELLI et al., 2013, DAMINELLI et al., 2016; SHIOZAKI et al., 2016; MENEGHINI et al., 2019). Com a DNR não foi diferente, a cardiotoxicidade característica da família das antraciclinas foi acentuadamente reduzida em um estudo feito com camundongos em nosso laboratório, além de potencializar a ação antitumoral em camundongos com melanoma quando comparada com a DNR comercial (TEIXEIRA et al., 2008; CONTENTE et al., 2014).

Devido ao sucesso da associação da DNR á LDE, neste estudo avaliamos a DNR associada a nanopartículas lipídicas LDE no tratamento de aterosclerose induzida por dieta rica em colesterol em coelhos, com o objetivo de aumentar o arsenal terapêutico de fármacos utilizados em tratamentos ateroscleróticos.

O protocolo com dieta rica em colesterol utilizado para a indução da aterosclerose já está consolidado na literatura e se mostrou eficaz em nossos trabalhos anteriores (TAVARES et al., 2011; MENEGHINI et al., 2019; WANG et al., 2017; BARBOZA et al., 2016). O consumo de ração e o peso dos animais foi semelhante em todo o protocolo nos dois grupos e a dieta rica em colesterol aumentou acentuadamente o colesterol total, o HDL-C e o não HDL-C quando comparado o início e o final da indução da aterosclerose nos animais.

A indução de aterosclerose por dieta rica em colesterol pode alterar o hemograma dos animais, principalmente a contagem de hemácias (UNRUH et al., 2005; SICO et al., 2018), além disso, estudos clínicos relataram que o uso da DNR comercial no tratamento de leucemias pode causar neutropenia, leucopenia, trombocitopenia e anemia (HOFLAND et al., 2005; SRANKOVA et al., 2019). Em nosso trabalho a diminuição de hemácias, hemoglobina e hematócrito e o aumento dos leucócitos aconteceu em ambos os grupos, demonstrando que a alteração pode ter sido pela dieta rica em colesterol e não pela influência do fármaco associado à LDE. Em relação a contagem dos neutrófilos, não houve 
diferença em nenhum dos períodos dos grupos LDE e LDE-DNR na porcentagem de neutrófilo mostrando que não houve a neutropenia pela influência do tratamento.

A função renal é uma covariável intrínseca no tratamento com a DNR, uma vez que uma parte da eliminação deste fármaco ocorre pela urina (TAKANASHI et al., 1975; WANG et al., 2019). Šimůnek et al. (2004), estudaram a formulação comercial de DNR em coelhos e ao utilizarem doses de $3 \mathrm{mg} / \mathrm{kg}$ por semana, houve uma alteração drástica na função renal desses animais. Em nosso estudo, não houve alterações na função renal do grupo tratado com LDE-DNR. Porém, os níveis de ureia estavam aumentados no grupo LDE quando comparado basal e pós-tratamento.

A aterosclerose é frequentemente relacionada com a doença gordurosa hepática não alcoólica, que é o tipo mais frequente de esteatose hepática. Diante disso, em coelhos alimentados com dieta rica em colesterol, as enzimas hepáticas (ALT/AST) estão geralmente elevadas (TAYLOR et al., 2018; WANG et al., 2018). Em nossas análises das enzimas hepáticas, a AST aumentou no grupo LDE-DNR quando comparado o período basal com o pré e o pós-tratamento. Estes resultados demonstraram que essa enzima hepática aumentou a partir do início da dieta rica em colesterol, com aumento mais acentuado ao fim do protocolo.

No presente estudo, as lesões ateroscleróticas no grupo LDE-DNR foram $50 \%$ menores quando comparadas às do grupo LDE, apesar de não haver diferença na proliferação celular entre os grupos. Estudos anteriores em nosso laboratório com outros quimioterápicos associados a LDE demonstraram que a nanopartícula, ao mudar os parâmetros de biodistribuição, dirige o fármaco para o sítio de ação de interesse. Ao centralizar o fármaco no sítio de ação, a LDE reduz a toxicidade desses tratamentos, além de diminuir a progressão da placa aterosclerótica dos animais com aterosclerose induzida por alimentação rica em colesterol (BULGARELLI et al., 2013; DAMINELLI et al., 2016; MENEGHINI et al., 2019).

Como os fatores inflamatórios podem promover o desenvolvimento da aterosclerose (LIBBY et al., 2019), Wang et al. (2020) estudaram camundongos 
com ApoE silenciada e analisaram marcadores inflamatórios na formação da aterosclerose, e a expressão de TNF- $\alpha$ e IL-6 estava aumentada nos camundongos controle onde só havia a indução da aterosclerose, comprovando que essas proteínas estão relacionadas com o desenvolvimento desta doença. Em nossas análises por Western blot, os marcadores inflamatórios TNF- $\alpha$ e IL-6 tiveram uma expressão acentuadamente menor no grupo LDE-DNR quando comparado ao grupo LDE, demonstrando que a LDE-DNR impediu a progressão da inflamação nos animais tratados. Porém, apesar da expressão proteica de IL-6 estar menor no grupo tratado com LDE-DNR, não houve diferença na expressão gênica de nenhuma das interleucinas estudadas quando comparado os grupos LDE-DNR e LDE.

Além disso, a migração e infiltração de monócitos e macrófagos também foram reduzidas, como demonstrado pela diminuição da expressão gênica de MCP-1 e VCAM-1, e a redução da expressão proteica de VCAM-1. Em um estudo de Cejkova et al., (2019), sobre o efeito das citocinas pro-inflamatórias liberadas pelo tecido adiposo visceral humano na adesão de monócitos ao endotélio, viram que as concentrações de MCP-1 no tecido adiposo correlacionou positivamente com a aderência de monócitos às células endoteliais, e aumentou a expressão do gene VCAM-1 estando diretamente relacionado ao agravamento da aterosclerose.

Os monócitos recrutados para o espaço subendotelial da aorta se diferenciam em macrófagos que fagocitam as lipoproteínas se diferenciando em células espumosas que contribuem para a progressão da placa aterosclerótica (ZEIBIG et al., 2019). Em nosso trabalho, houve uma menor expressão do marcador de macrófagos nas aortas do grupo LDE-DNR comparado com o grupo LDE, o que demonstra uma lesão aterosclerótica menos avançada nesses coelhos.

Analisamos também o VEGF que é um importante fator angiogênico para induzir proliferação e migração de células endoteliais. A expressão dessa proteína melhora a permeabilidade vascular que permite fornecer nutrientes e promove a infiltração de macrófagos, espessamento da parede dos vasos, deposição lipídica, inflamação e progressão da lesão aterosclerótica (CELLETTI et al., 2001; FAN et al., 2019). Observamos menor expressão do VEGF no grupo LDE-DNR 
comparado com o grupo LDE, o que pode significar que a LDE-DNR diminuiu a angiogênese nas células endoteliais nesses animais, contribuindo assim para menor proliferação na íntima.

Ademais, segundo Gautier et al., (2009) a apoptose de macrófagos e de células do músculo liso vascular em placas ateroscleróticas avançadas contribui para o desenvolvimento e progressão da doença, pois a morte celular de macrófagos contribui para a formação do núcleo necrótico da placa, além de possuir propriedades pró-inflamatórias em parte como resultado de presença de fosfolipídios oxidados na superfície das células apoptóticas. Esse processo apoptótico é governado por Bax e por proteases específicas do aspartato de cisteína, denominadas caspases (GROOTAERT et al., 2016). Em nosso trabalho, as expressões proteicas dos fatores pró apoptóticos caspase 3, caspase 9 e Bax foram menores nas lesões das aortas do grupo LDE-DNR quando comparado ao grupo LDE demonstrando que houve menos apoptose no nosso grupo tratado, devido a estes animais apresentarem menos placas ateroscleróticas.

Além disso, as MMPs são proteínas chave no processo da aterosclerose, elas decompõem os componentes da matriz extracelular e promovem a migração de células do músculo liso vascular (CHOU et al., 2019). Em um estudo de Ren et al., (2018), a expressão de MMP-2 estava aumentada com a indução de aterosclerose por nicotina e silenciamento de apo-E em camundongos. Em nosso trabalho, a expressão proteica de MMP-2 e a expressão gênica de MMP-12 foi menor no grupo LDE-DNR quando comparado com o grupo LDE.

As antraciclinas podem facilitar a liberação de citocinas pró-inflamatórias, estimulando macrófagos que desempenham um papel no desenvolvimento da cardiotoxicidade (SCHUBERT et al., 2007). O tratamento de células com doxorrubicina, mostrou causar uma expressão aumentada de IL -1 $1 \beta$, IL-6 e MCP1, por meio da ativação da via NF-kB (PENG et al., 2020). Por isso, também fizemos as análises de expressão gênica no tecido cardíaco e não houve diferença entre os grupos LDE-DNR e LDE em nenhum dos marcadores analisados (VCAM-1, IL-18, IL-10 e IL-1ß), mostrando que a LDE-DNR não influenciou na inflamação a nível molecular no tecido analisado. 
Devido ao alto risco de cardiotoxicidade, as antraciclinas possuem um uso limitado e a toxicidade cardíaca causada por elas é comumente avaliada pelo ecocardiograma por disfunção sistólica e diastólica do ventrículo esquerdo, fração de ejeção e massa cardíaca (THAVENDIRANATHAN et al., 2013; POKORNA et al., 2019). Em um estudo de Talavera et al., (2015) desenvolveram um protocolo de cardiomiopatia induzida por antraciclina, adequada para ser utilizada em estudos, e demonstraram que $92 \%$ dos coelhos que utilizaram uma dose de $4 \mathrm{mg} / \mathrm{kg}$ de DNR durante 6 semanas tiveram uma cardiomiopatia dilatada. Além disso, eles testaram uma dose de $6 \mathrm{mg} / \mathrm{kg}$ durante 4 a 5 semanas que resultou na morte de $50 \%$ dos coelhos, impedindo a continuação dos estudos com essa dose. Em nosso estudo, com uma dose de $6 \mathrm{mg} / \mathrm{kg}$ durante 4 semanas, nenhum animal morreu durante o protocolo e observou-se que as funções sistólica e diastólica foram preservadas no grupo LDE-DNR quando comparado com os grupos LDE e controle saudável e não houve diferença na massa cardíaca entre os 3 grupos. Ademais, após a eutanásia medimos o peso relativo do coração desses animais, e os coelhos tratados com LDE-DNR não apresentaram diferença demonstrando que provavelmente não houve dilatação cardíaca, enquanto no grupo LDE o peso relativo do coração estava maior que nos controles saudáveis. 


\section{CONCLUSÃO}

Concluímos que a DNR associada a LDE se mostrou eficaz no tratamento da aterosclerose induzida por dieta rica em colesterol em coelhos, pois reduziu as lesões ateroscleróticas da aorta comparado com os coelhos do grupo LDE.

O tratamento com LDE-DNR diminuiu acentuadamente a inflamação e a morte celular na aorta dos animais. Além disso, esta formulação foi notável ao reduzir as toxicidades do fármaco no grupo de coelhos tratados com LDE-DNR, uma vez que animais não apresentaram as toxicidades comumente associadas ao tratamento com a DNR na formulação comercial. 


\section{REFERÊNCIAS BIBLIOGRÁFICAS}

ADES A. et al. Uptake of a cholesterol-rich emulsion by neoplastic ovarian tissues. Gynecol Oncol. 2001;82(1):84-87.

ALFONSO F. et al. RIBS-III Study Investigators (under the auspices of the Working Group on Interventional Cardiology of the Spanish Society of Cardiology). Implantation of a drug-eluting stent with a different drug (switch strategy) in patients with drug-eluting stent restenosis. Results from a prospective multicenter study (RIBS III [Restenosis Intra-Stent: Balloon Angioplasty Versus Drug-Eluting Stent]). JACC Cardiovasc Interv. 2012 Jul;5(7):728-37. doi: 10.1016/j.jcin.2012.03.017.

AL-GOBARI M. et al. No benefits of statins for sudden cardiac death prevention in patients with heart failure and reduced ejection fraction: A meta-analysis of randomized controlled trials. PLoS One. 2017 Feb 6;12(2):e0171168.

BARBOZA LN. et al. Atheroprotective effects of Cuphea carthagenensis (Jacq.) J. F. Macbr. in New Zealand rabbits fed with cholesterol-rich diet. J Ethnopharmacol. 2016 Jul 1;187:134-45.

BULGARELLI A. et al. Anti-atherogenic effects of methotrexate carried by a lipid nanoemulsion that binds to LDL receptors in cholesterol-fed rabbits. Cardiovasc Drugs Ther. 2013. Dec; 27(6):531-9.

CAPRANICO G. et al. Different patterns of gene expression of topoisomerase II isoforms in differentiated tissues during murine development. Biochim Biophys Acta. 1992 Aug 17;1132(1):43-8.

CELLETTI FL. et al. Vascular endothelial growth factor enhances atherosclerotic plaque progression. Nat Med. 2001 Apr;7(4):425-9.

CEJKOVA S. et al. The effect of cytokines produced by human adipose tissue on monocyte adhesion to the endothelium. Cell Adh Migr. 2019 Dec;13(1):293-302. 
CHACRA, APM; SANTOS FILHO, RD. Quando e como avaliar o risco cardiovascular global em indivíduos aparentemente normais - ou check-up para todos. Rev. Soc. Cardiol. Estado de São Paulo; 29(1): 46-52, 2019.

CHOU CC. et al. Anti-Atherosclerotic Effect of Hibiscus Leaf Polyphenols against Tumor Necrosis Factor-alpha-Induced Abnormal Vascular Smooth Muscle Cell Migration and Proliferation. Antioxidants (Basel). 2019 Dec 5;8(12). pii: E620.

CONTENTE TC. et al. Association of daunorubicin to a lipid nanoemulsion that binds to low-density lipoprotein receptors enhances the antitumor action and decreases the toxicity of the drug in melanoma-bearing mice. $\mathbf{J}$ Pharm Pharmacol. 2014.Dec;66(12):1698-709.

COUTO RD. et al. Deposition of free cholesterol in the blood vessels of patients with coronary artery disease: a possible novel mechanism for atherogenesis. Lipids. 2007 May;42(5):411-8. Epub 2007 Apr 19.

DAMINELLI EN. et al. Reduction of Atherosclerotic Lesions by the Chemotherapeutic Agent Carmustine Associated to Lipid Nanoparticles. Cardiovasc Drugs Ther. 2016 Oct;30(5):433-443.

DE GAETANO M. et al. M1- and M2-Type Macrophage Responses Are Predictive of Adverse Outcomes in Human Atherosclerosis. Front Immunol. $2016 \mathrm{Jul}$ 19;7:275.

DORLHIAC-LLACER PE. et al. In vitro cytotoxicity of the LDE: daunorubicin complex in acute myelogenous leukemia blast cells. Braz J MedBiol Res. 2001;34(10):1257-63.

DUBEY R. et al. Daunorubicin forms a specific complex with a secreted serine protease of Streptomycespeucetius. World J Microbiol Biotechnol. 2014 Jan;30(1):253-61.

FAN M. et al. Adipose-Derived Stem Cell Transplantation Inhibits Vascular Inflammatory Responses and Endothelial Dysfunction in Rats with Atherosclerosis. Yonsei Med J. 2019 Nov;60(11):1036-1044. 
GAUTIER EL. et al. Macrophage apoptosis exerts divergent effects on atherogenesis as a function of lesion stage. Circulation. 2009 Apr 7;119(13):1795804.

GROOTAERT MO. et al. Caspase-3 Deletion Promotes Necrosis in Atherosclerotic Plaques of ApoE Knockout Mice. Oxid Med Cell Longev. 2016;2016:3087469.

GRAZIANI SR. et al. Uptake of a cholesterol rich-emulsion by breast cancer. Gynecol Oncol. 2002;85:493-7.

GRAZIANI SR. et al. Phase II study of paclitaxel associated with lipid core nanoparticles (LDE) as third-line treatment of patients with epithelial ovarian carcinoma. Med Oncol. 2017 Sep;34(9):151.

HANSSON GK, ROBERTSON AK, SÖDERBERG-NAUCLÉR C. Inflammation and atherosclerosis. Annu Rev Pathol. 2006;1:297-329.

HO YK. et al. Low-Density Lipoprotein (LDL) Receptor Activity in Human Acute Myelogenous Leukemia Cells. Blood. 1978;52:1099-114.

HOFLAND KF. et al. Dexrazoxane protects against myelosuppression from the DNA cleavage-enhancing drugs etoposide and daunorubicin but not doxorubicin. Clin Cancer Res. 2005 May 15;11(10):3915-24.

JAIN TK. et al. Iron oxide nanoparticles for sustained delivery of anticancer agents. Mol Pharm. 2005 May-Jun;2(3):194-205.

JENKINS JR. et al. Isolation of cDNA clones encoding the beta isozyme of human DNA topoisomerase II and localisation of the gene to chromosome 3p24. Nucleic Acids Res. 1992 Nov 11; 20(21): 5587-5592.

LAGARES $\mathrm{MH}$. et al. Analysis of p53 gene polymorphism (codon 72) in symptomatic patients with atherosclerosis. Genet Mol Res. 2017 Aug 17;16(3). doi: $10.4238 / g m r 16039721$.

LANG R.M., et al., Recommendations for chamber quantification: a report from the American Society of Echocardiography's Guidelines and Standards Committee and the Chamber Quantification Writing Group, developed in conjunction with the 
European Association of Echocardiography, a branch of the European Society of Cardiology. J Am Soc Echocardiography, 2005. 18(12): p. 1440-63.

LIBBY P, et al. Atherosclerosis. Nat Rev Dis Primers. 2019 Aug 16;5(1):56.

LIU S, FANG F, FAN G. Potassium selenocyanoacetate reduces the blood triacylglycerol and atherosclerotic plaques in high-fat-dieted mice. Cardiovasc Diagn Ther. 2019 Dec;9(6):561-567.

LOTFI K, ZACKRISSON AL, PETERSON C. Comparison of idarubicin and daunorubicin regarding intracellular uptake, induction of apoptosis, and resistance. Cancer Lett. 2002 Apr 25;178(2):141-9.

LUNDE NN. et al. Legumain is upregulated in acute cardiovascular events and associated with improved outcome - potentially related to anti-inflammatory effects on macrophages. Atherosclerosis. 2019 Dec 14. pii: S0021-9150(19)31626-0.

LYU YL. et al. Topoisomerase II beta mediated DNA double-strand breaks: implications in doxorubicin cardiotoxicity and prevention by dexrazoxane. Cancer Res. 2007 Sep 15;67(18):8839-46.

MAILLET A. et al. Modeling doxorubicin-induced cardiotoxicity in human pluripotent stem cell derived-cardiomyocytes. Sci Rep. 2016; 6: 25333. Published online 2016 May 4. doi: 10.1038/srep25333

MARANHÃO RC. et al. Increased plasma removal of microemulsions resembling the lipid phase of low-density lipoproteins (LDL) in patients with acute myeloid leukemia: a possible new strategy for the treatment of the disease. Braz $\mathbf{J}$ Med Biol Res. 1992;25(10):1003-7.

MARANHÃO RC. et al. Metabolic behavior in rats of a nonprotein microemulsion resembling low density lipoprotein. Lipids. 1993; 28:691-6.

MARANHÃO RC. et al. Plasma kinetics and biodistribution of a lipid emulsion resembling low-density lipoprotein in patients with acute leukemia. Cancer Res.

$1994 ; 54: 1-7$. 
MARANHÃO RC. et al. Plasma kinetic behavior in hyperlipidemic subjects of a lipidic microemulsion that binds to LDL receptors. Lipids. 1997; 32:627-33.

MARANHÃO RC. et al. Association of carmustine with a lipid emulsion: in vitro, in vivo and preliminary studies in cancer patients. Cancer Chemother Pharmacol. 2002;49:487-98.

MARANHÃO RC. et al. Paclitaxel associated with cholesterol-rich nanoemulsions promotes atherosclerosis regression in the rabbit. Atherosclerosis. 2008; 197:959-66.

MENEGHINI BC. et al. Lipid core nanoparticles as vehicle for docetaxel reduces atherosclerotic lesion, inflammation, cell death and proliferation in an atherosclerosis rabbit model. Vascul Pharmacol. 2019 Apr;115:46-54.

MOURA JA. et al. Novel formulation of a methotrexate derivative with a lipid nanoemulsion. Int J Nanomedicine. 2011;6:2285-95. 
NAOUM FA. et al. Plasma kinetics of a cholesterol-rich microemulsion in subjects with heterozygous beta-thalassemia. Am J Hematol Dec. 2004;77(4):340-5.

PEÑA E. et al. mCRP triggers angiogenesis by inducing F3 transcription and TF signalling in microvascularendothelial cells. Thromb Haemost. 2017 Jan 26;117(2):357-370. doi: 10.1160/TH16-07-0524.

PENG W. et al. Teneligliptin prevents doxorubicin-induced inflammation and apoptosis in H9c2 cells. Arch Biochem Biophys. 2020 Apr 15;683:108238. doi: 10.1016/j.abb.2019.

POKORNA Z. et al. In vitro and in vivo investigation of cardiotoxicity associated with anticancer proteasome inhibitors and their combination with anthracycline. Clin Sci (Lond). 2019 Aug 27;133(16):1827-1844.

REN A. et al. Nicotine promotes atherosclerosis development in apolipoprotein Edeficient mice through $\alpha 1-n A C h R$. J Cell Physiol. 2018 Dec 26. doi: 10.1002/jcp.27728.

ROBERT J. [Pharmacokinetics of new anthracyclines]. Bull Cancer. 1988;75(2):167-74.

ROBERT J. et al. Pharmacokinetics and metabolism of 4'-iodo-4'-deoxydoxorubicin in humans. J Clin Oncol. 1992 Jul;10(7):1183-90.

RODRIGUES DG. et al. Use of a cholesterol- rich emulsion that binds to lowdensity lipoprotein receptors as a vehicle for paclitaxel. J Pharm and Pharmacol. 2002;54(6):765-72.

RODRIGUES DG, et al. Improvement of paclitaxel therapeutic index by derivatization and association to a cholesterol-rich microemulsion: in vitro and in vivo studies. Cancer Chemother Pharmacol. 2005;55(6):565-76.

RUAN Y. et al. Cardiovascular disease (CVD) and associated risk factors among older adults in six low-and middle-income countries: results from SAGE Wave 1. BMC Public Health. 2018; 18: 778. 
RUNHUA M. et al. FSTL3 Induces lipid accumulation and inflammatory response in macrophages and associates with atherosclerosis. J Cardiovasc Pharmacol. 2019 Dec;74(6):566-573.

SALVATORELLI E. et al. Low-Dose Anthracycline and Risk of Heart Failure in a Pharmacokinetic Model of Human Myocardium Exposure: Analog Specificity and Role of Secondary Alcohol Metabolites. J Pharmacol Exp Ther. 2018 Feb;364(2):323-331.

SÁNCHEZ-ROA PM. et al. Systemic atherosclerotic plaque vulnerability in patients with Coronary Artery Disease with a single Whole Body FDG PET-CT scan. Asia Ocean J Nucl Med Biol. 2020 Winter;8(1):18-26.

SANDA GM. et al. Oxidized LDL-Exposed Human Macrophages Display Increased MMP-9 Expression and Secretion Mediated by Endoplasmic Reticulum Stress. J Cell Biochem. 2017 Apr;118(4):661-669.

SAPETTO-REBOW B. et al. Maternal topoisomerase II alpha, not topoisomerase II beta, enables embryonic development of zebrafish top2a-/- mutants. BMC Dev Biol. 2011 Nov 23;11:71. doi: 10.1186/1471-213X-11-71.

SCHUBERT C. et al. The association between fatigue and inflammatory marker levels in cancer patients: a quantitative review. Brain Behav Immun. 2007;21:413

SHADLE SE. et al. Daunorubicin cardiotoxicity: evidence for the importance of the quinone moiety in a free-radical-independent mechanism. Biochem Pharmacol. 2000 Nov 15;60(10):1435-44.

SHIOZAKI AA. et al. Treatment of patients with aortic atherosclerotic disease with paclitaxel-associated lipid nanoparticles. Clinics (Sao Paulo). 2016 Aug;71(8):435-9. doi: 10.6061/clinics/2016(08)05.

SICO JJ. et al. Association between admission haematocrit and mortality among men with acute ischaemic stroke. Stroke Vasc Neurol. 2018 Apr 24;3(3):160-168.

SILBER R. et al. Metabolic activation of $\mathrm{N}$-acylanthracyclines precedes their interaction with DNA topoisomerase II. NCI Monogr. 1987;(4):111-5. 
ŠIMŮNEK T. et al. Rabbit model for in vivo study of anthracycline-induced heart failure and for the evaluation of protective agents. Eur. J. Heart Fail. 2004 Jun;6(4):377-87.

SRANKOVA J. et al. Pegfilgrastim and linagliptin potentiate chemoattraction of Ccr2 and Cd44 stem cells accompanied by alterations of cardiac Hgf, Igf-1 and Mcp-1 in daunorubicin cardiomyopathy. J Pharm Pharmacol. 2019 Sep;71(9):1440-1450.

SWIFT LP. et al. The cardio-protecting agent and topoisomerase II catalytic inhibitor sobuzoxane enhances doxorubicin-DNA adduct mediated cytotoxicity. Cancer Chemother Pharmacol. 2008 Apr;61(5):739-49. Epub 2007 Jun 27.

SZWED M. et al. Transferrin as a drug carrier: Cytotoxicity, cellular uptake and transport kinetics of doxorubicin transferrin conjugate in the human leukemia cells. Toxicol In Vitro. 2014 Mar; 28(2):187-97.

TAKANASHI S. et al. Daunorubicin metabolites in human urine. J Pharmacol Exp Ther. 1975 Oct;195(1):41-9.

TALAVERA J. et al. An Upgrade on the Rabbit Model of AnthracyclineInduced Cardiomyopathy: Shorter Protocol, Reduced Mortality, and Higher Incidenc e of Overt Dilated Cardiomyopathy. Biomed Res Int. 2015;2015:465342.

TAVARES ER. et al. Reduction of atherosclerotic lesions in rabbits treated with etoposide associated with cholesterol-rich nanoemulsions. Int $\mathbf{J}$ Nanomedicine. 2011;6:2297-304. doi: 10.2147/IJN.S24048. Epub 2011 Oct 12.

TAYLOR E. et al. MRI of atherosclerosis and fatty liver disease in cholesterol fed rabbits. J TransI Med. 2018 Aug 1;16(1):215.

TEIXEIRA RS. et al. Delivery of daunorrubicin to cancer cells with decreased toxicity by association with a lipidic nanoemulsion that binds to LDL receptors. $\mathbf{J}$ Pharm Pharmacol. 2008;1287-95.

THAVENDIRANATHAN P. et al. Reproducibility of echocardiographic techniques for sequential assessment of left ventricular ejection fraction and volumes: 
application to patients undergoing cancer chemotherapy. J Am Coll Cardiol. 2013 Jan 8;61(1):77-84.

VALDUGA CJ. et al. Use of a cholesterol-rich microemulsion that binds to lowdensity lipoprotein receptors as vehicle for etoposide. J Pharm Pharmacol. 2003;55:1615-22.

WANG J. et al. Synthesis and antitumor efficacy of daunorubicin-loaded magnetic nanoparticles. Int J Nanomedicine. 2011;6:203-11.

WANG L. et al. Regression of atherosclerosis with apple procyanidins by activating the ATP-binding cassette subfamily $A$ member 1 in a rabbit model. Atherosclerosis. 2017 Mar;258:56-64.

WANG N. et al. Combination of tanshinone IIA and astragaloside IV attenuate atherosclerotic plaque vulnerability in $\mathrm{ApoE}(-/)$ mice by activating PI3K/AKT signaling and suppressing TRL4/NF-KB signaling. Biomed Pharmacother. 2020 Mar;123:109729.

WANG Q. et al. Population Pharmacokinetics and Exposure-Response Analyses for CPX-351 in Patients With Hematologic Malignancies. J Clin Pharmacol. 2019 May;59(5):748-762.

WANG Y. et al. Establishment of a novel non-alcoholic fatty liver disease model using cholesterol-fed rabbits with reference to the potential role of endoplasmic reticulum stress. Mol Med Rep. 2018 Sep; 18(3): 2898-2904.

YAO J. et al. Sonodynamic Therapy Suppresses Neovascularization in Atherosclerotic Plaques via Macrophage Apoptosis-Induced Endothelial Cell Apoptosis. JACC Basic Transl Sci. 2019 Dec 26;5 Biomed Res Int. 2015; 2015: 465342.

ZEIBIG S. et al. The Scavenger Receptor CD68 Regulates Platelet Mediated Oxidized Low-Density Lipoprotein (oxLDL) Deposition in Atherosclerotic Vessels at an Early Stage of Atherosclerosis in LDLR-//ApoBec-/- Mice. Cell Physiol Biochem. 2019; 52(4):681-695. 
ZHANG W. Nanoparticle aggregation: principles and modeling. Adv Exp Med Biol. 2014;811:19-43. 